\title{
State-Dependent Pricing and Optimal Monetary Policy*
}

\author{
Denny $\operatorname{Lie}^{\dagger}$ \\ The University of Sydney
}

This Version: December 2011

First Version: December 2009

\begin{abstract}
This paper analyzes optimal monetary policy under precommitment in a state-dependent pricing (SDP) environment. Under SDP, monopolistically competitive firms are allowed to endogenously change the timing of price adjustments. I show that this endogenous timing of price adjustment alters the tradeoff and the cost of inflation variation faced by the monetary authority in comparison to the standard time-dependent pricing (TDP) assumption. In particular, it is desirable to let inflation vary more under SDP. Despite the change in the policy tradeoff, however, the optimal response under SDP to either a productivity or a government purchase shock under the timeless perspective (long-run) policy can still be characterized as an approximate price stability rule. Additionally, this paper studies the optimal policy start-up problem related to the cost of adopting the timeless perspective policy instead of the true Ramsey policy. The SDP assumption leads to different start-up dynamics compared to the dynamics under the TDP assumption in several important ways. In particular, the change in the policy tradeoff gives rise to much higher start-up inflation under SDP.
\end{abstract}

JEL Classification: E31, E52, E61

Keywords: optimal monetary policy, state-dependent pricing, start-up problem.

${ }^{*}$ I wish to thank Richard Dennis, Chris Edmond, Simon Gilchrist, Fabiá Gumbau-Brisa, Andrew John, Mike Johnston, Tim Kam, Bob King, Giovanni Olivei, Ali Ozdagli, and Adrien Verdelhan for valuable comments and suggestions. Comments by seminar participants at Boston University, Federal Reserve Bank of Boston, University of Sydney, University of Melbourne, City University of Hong Kong, Reserve Bank of Australia, 2011 Asian Meetings of the Econometric Society, and Australian National University are gratefully acknowledged. All errors are mine.

${ }^{\dagger}$ School of Economics | Faculty of Arts and Social Sciences | The University of Sydney | Email: denny.lie@sydney.edu.au 


\section{Introduction}

This paper studies optimal monetary policy under precommitment in a state-dependent pricing environment in contrast to the standard assumption of time-dependent pricing. Currently there are a large and growing number of studies in the literature that analyze the nature of optimal monetary policy. A common denominator of all these studies is that the nature of the pricing friction responsible for the presence of predetermined prices is time-dependent. That is, firms have no choice about the timing of their price adjustments, as in the familiar work of Calvo (1983) and Taylor (1980). One reason why time-dependent pricing (henceforth, TDP) models are popular in optimal monetary policy analysis is that there is no need to track the price distribution of firms and the frequency of price adjustment - for example, in Calvo (1983), a single parameter, the probability of price adjustment, is a sufficient statistic to summarize the entire price distribution, given the reset price and the lagged aggregate price level. In state-dependent pricing (henceforth, SDP) models, one needs to track many state variables involving predetermined prices and the distribution of firms according to the time since the last price adjustment, further complicating the models and their analyses.

Yet, there are several reasons why it is desirable to move away from the realm of TDP in optimal monetary policy analysis. The endogenous timing of price adjustment under SDP may alter the inflation-output tradeoff faced by the monetary authority. Since monetary policy works primarily because of the existence of this tradeoff, such a modification in the tradeoff may in turn lead to a different prescription as to the optimal conduct of monetary policy. In such an environment, the monetary authority needs to take into account the effect of its policy on the frequency of price adjustment, since this also affects the course of real economic activity. The literature ignore the incorporation of SDP arguably because there is a belief that TDP is a good approximation to the more-realistic assumption of SDP (see e.g. Klenow and Kryvtsov, 2008). However, this is only true in an economy with small and stable inflation. When inflation is high and highly variable, SDP is a better and more accurate representation of the true firms' price adjustment decision. How should monetary policy be conducted in such an environment is therefore an important question for academics and practitioners alike. In terms of data evidence, there is growing evidence documenting state dependence in firms' price adjustment activities. For example, Nakamura and Steinsson (2008), among others, show that it is the frequency, rather than the size of price adjustment, that has a strong positive correlation with inflation - this evidence is more consistent with the SDP 
assumption.

The specific state-dependent pricing framework used in this paper is the model of Dotsey, King, and Wolman (1999), in which firms are allowed to endogenously change their timing of price adjustments by paying a small fixed menu cost. ${ }^{1}$ In terms of the optimal monetary policy approach, this paper follows the common practice in the public finance literature, for instance, as in Chamley (1986). Other examples of optimal monetary policy studies in the literature using this approach include Erceg, Anderson, and Levin (2000); Khan, King, and Wolman (2003); Levin et. al. (2005); Schmitt-Grohe and Uribe (2005, 2007), all of whom analyze a closed-economy setting, while Benigno and Benigno (2003) and Faia and Monacelli (2004) analyze an open-economy setting. This paper thus departs from the widespread use of the linear-quadratic (LQ) approach, as surveyed in Clarida, Galí, and Gertler (1999). In such an approach, one needs an explicit reduced-form equation involving inflation dynamics (the Phillips curve) and the literature has not provided a convenient and thorough representation of state-dependent pricing for that purpose. ${ }^{2}$ Furthermore, the public finance approach uses a direct and natural criterion for the evaluation of welfare: households' lifetime utility. In this approach, market distortions (inefficiencies) are identified and monetary policy affects welfare through its influence on the variations in these distortions.

Specifically, there are four set of distortions present in the model: (i) the markup distortion that arises from firms' monopoly power, which causes market-generated output level to be inefficient; (ii) the relative-price distortion arising from firms' asynchronous price-adjustment process; (iii) the monetary (exchange) distortions due to the use of money and credit to purchase final consumption goods; and (iv) the menu cost distortion due to the fixed cost of price adjustment. There are generally tradeoffs between these distortions requiring the monetary authority to balance the extent of these distortions in the process of achieving the socially optimum allocation. The monetary authority is assumed to solve a precommitment Ramsey problem in a decentralized economy setting where the private sector's efficiency conditions must be respected at all times.

Another contribution of this paper is in terms of the method used to solve for the optimal policy problem. Starting from the work of King, Plosser, and Rebelo (1988), most dynamic stochastic general equilibrium models are solved using a first-order (linear) approximation method. Many

\footnotetext{
${ }^{1}$ The choice of which SDP model to use matters little for the general results in this paper. One can use, for example, the model of Golosov and Lucas (2007) instead of Dotsey, King, and Wolman (1999). The key ingredient for the results is that firms are allowed to respond to shocks and changing states of the economy by adjusting their prices - subject to some regularity conditions, e.g. the optimal reset price is increasing with inflation.

${ }^{2}$ Studies that attempt to derive a state-dependent pricing Phillips curve include Bakhshi, Khan, and Rudolf (2007), Gertler and Leahy (2008), and Hernandez (2004).
} 
have argued that linear approximations to SDP models miss the state-dependence nature and the nonlinearity property of such models. In light of recent development in the literature on second-order approximation solution methods - for instance, Kim et. al. (2008), Lombardo and Sutherland (2007), and Schmitt-Grohe and Uribe (2004) — this paper shows that one can easily solve and analyze this class of models to the second order. In particular, I use the recent perturbation approach of Johnston, King, and Lie (2009). This approach is convenient and straightforward since the second-order approximate solution can be directly cast in a state-space form, permitting a ready comparison to the first-order approximate solution. ${ }^{3}$

The first finding of this paper involves the timeless perspective (Woodford, 2003) responses to a temporary productivity shock and a temporary government purchase shock. I show that the optimal response to either shock can be characterized as an approximate price stability rule, in a sense that the price level is still largely stabilized around its deterministic trend. Hence, the optimal policy under SDP is to closely replicate the dynamics under the TDP assumption previously found in studies such as Khan, King, and Wolman (2003) and Schmitt-Grohe and Uribe (2007). Despite the close association to optimal response under TDP, the presence of endogenous timing of price adjustment under SDP alters the policy tradeoff faced by the monetary authority. In particular, I show that it is optimal for the monetary authority to let inflation vary more under SDP. As we shall see, this somewhat smaller focus on inflation stabilization is precisely due the changing nature of the policy tradeoff under SDP.

Additionally, this paper also studies the optimal monetary policy start-up problem. As described in Woodford (2003), a timeless perspective policy is a policy that is assumed to have been long implemented. Most studies on optimal precommitment monetary policy have focused exclusively on optimal timeless-perspective policies. However, even though a precommitment policy is optimal from the timeless perspective, it is not the true Ramsey solution that maximizes the welfare of the representative agent. The true Ramsey solution specifies that the monetary authority should treat the early period of precommitment policy implementation differently than subsequent periods. This is because in the starting period, there is no past commitment that the monetary authority must follow through. With monopolistically competitive firms and nominal price rigidity as in the model in this paper, this so-called start-up problem is manifested in the optimal decision

\footnotetext{
${ }^{3}$ An earlier version of this paper also presents the optimal second-order approximate responses to various shocks. The current version of the paper eliminates these results and only illustrates that such an analysis is feasible and is potentially important.
} 
of the monetary authority to temporarily stimulate the economy by generating surprise inflation in the starting period. It is optimal to do so since the economy operates inefficiently due to the presence of firms' monopoly power. Given the suboptimality of the timeless perspective policy, it is of interest to investigate the cost of adopting this policy instead of the true Ramsey policy. The start-up problem essentially measures the welfare loss of ignoring this starting period of policy implementation. Furthermore, the start-up problem analysis more clearly highlights the modification in both inflation-output and policy tradeoffs since in such a case the general price level deviates further away from its deterministic path.

I find that incorporating SDP in the model leads to different start-up dynamics compared to the dynamics under the standard TDP assumption along several interesting and important dimensions. In particular, it is optimal to generate much higher start-up inflation despite the fact that the monetary authority is shown to have less leverage over real activity in the presence of SDP. This result is once again due to the subtle modification to the policy tradeoff involving the lower cost of inflation variation on the relative-price distortion. The welfare improvement from generating this surprise inflation, however, is shown to be relatively small. Thus, the timeless-perspective policy may be a good approximation to the true Ramsey policy.

The rest of this paper is organized as follows. Section 2 presents the model used in the analysis, and lays out the optimal monetary policy approach and the solution methodology. I also present the calibration of the model and the steady-state property under the optimal precommitment policy. Section 3 analyzes the timeless perspective (long-run) responses to the two shocks up to the firstorder approximation. Section 4 considers some robustness analyses. Section 5 investigates the start-up problem. Section 6 concludes.

\section{The model}

This section first presents the private sector's efficiency conditions of the model economy. The description of the optimal precommitment policy problem, in which all the private sector's efficiency conditions must be respected at all times, follows next. 


\subsection{The private sector's constraints}

The private sector consists of two sets of agents, a representative household and a continuum of intermediate-good firms on a unit measure. These private sector agents solve dynamic optimization problems given the state of the economy and the knowledge of the optimal policy rule employed by a committed monetary policy authority. ${ }^{4}$ The economy has two sets of state variables. The first set, $s_{t}^{1}$, concerns those state variables involving the private sector. Further, $s_{t}^{1}$ can be decomposed into the endogenous state vector, $k_{t}$ and the exogenous state vector, $\varsigma_{t}$. Hence, $s_{t}^{1}=\left(k_{t}, \varsigma_{t}\right)$. The exogenous state vector evolves according to the process $\varsigma_{t+1}=v\left(\varsigma_{t}, \eta_{t+1}\right)$, where $\eta_{t}$ is a vector of serially independent shocks. Lagged optimal policy multipliers, collected in a vector $s_{t}^{2}$, are the additional set of state variables. These multipliers summarize the past policy plans of the monetary authority that must be respected under the precommitment policy. The entire set of state variables is $s_{t}$, with $s_{t}=\left(s_{t}^{1}, s_{t}^{2}\right)$. Later in the section the individual elements of these state vectors will be clarified. Aggregate fluctuations are driven by two exogenous shocks, a productivity shock and a government purchase shock, which affect $s_{t}$.

\subsubsection{Intermediate-good firms}

There is a continuum of monopolistically competitive firms in the economy, indexed by $i \in[0,1]$, where each firm produces a differentiated intermediate good. These varieties of intermediate goods are bundled together into a final consumption good according to the constant elasticity of substitution (CES) aggregator,

$$
c_{t}=\left[\int_{0}^{1} c_{t}(i)^{\frac{\varepsilon-1}{\varepsilon}}\right]^{\frac{\varepsilon}{\varepsilon-1}},
$$

where $\varepsilon$ is both the constant elasticity of substitution and the relative demand elasticity for any variety $i$. There is also a government that purchases final consumption goods $\left(g_{t}\right)$ aggregated according to the same process. ${ }^{5}$ Let $p_{t}(i)$ be the relative price of variety $i$. The demand for variety $i$ is then given by $p_{t}(i)^{-\varepsilon} y_{t}=p_{t}(i)^{-\varepsilon}\left(c_{t}+g_{t}\right)$, where $y_{t}=c_{t}+g_{t}$ is the aggregate economy-wide output.

Each firm $i$ is subject to a fixed cost that needs to be paid every time it adjusts its (nominal) price. As in Dotsey, King, and Wolman (1999), the fixed adjustment costs (in labor units) are het-

\footnotetext{
${ }^{4}$ This paper abstracts from deriving such an optimal policy rule. Instead, I search for the allocation consistent with this optimal policy rule.

${ }^{5}$ Government purchases are assumed to be financed by lump-sum taxes.
} 
erogenous across firms and are drawn each period independently from a time-invariant continuous distribution with cumulative distribution function $(\mathrm{CDF}) G(\cdot)$. Firms that choose not to adjust prices, after observing the fixed cost draw and the state of the economy, do not have to pay these fixed costs but must keep the nominal price from the previous period. This specification means that, at any given period, firms will be distributed according to "the time since the last price adjustment" $j$, with $j=0$ indicating those firms that adjust in the current period. Let $\omega_{j, t}$ be the end-of-period fraction of firms that last adjusted their prices $j$ periods ago. ${ }^{6}$ These variables summarize the distribution of firms according to the time since the last price adjustment and can be expressed as

$$
\omega_{j, t}=\left(1-\alpha_{j t}\right) \omega_{j-1, t-1}
$$

for $j=1, \ldots, J-1$, where $J$ is the longest period of price fixity that has to be endogenously determined in the steady state. ${ }^{7}$ For each $j$, the variable $\alpha_{j, t}$ is the fraction of firms $j$ - firms that last adjusted prices $j$ periods ago - that decide to adjust at the beginning of period $t$ right after the fixed cost draw. Since the fraction of all firms sums to one, the fraction of adjusting firms in the current period $t\left(\omega_{0, t}\right)$ is then given by

$$
\omega_{0, t}=1-\sum_{j=1}^{J-1} \omega_{j, t}
$$

Note that in the current SDP specification, both $\left\{\alpha_{j t}\right\}_{j=1}^{J-1}$ and $\left\{\omega_{j, t}\right\}_{j=0}^{J-1}$ are determined endogenously and depend on aggregate variables and firms' prices. Under the TDP assumption as in Levin (1991) and Khan, King, and Wolman (2003), these variables are exogenous and become parameters of the model. ${ }^{8}$

Next, I describe the dynamic maximization problem for adjusting firms. Firms are monopolistically competitive and use labor as the only production input. Specifically, the production function for any firm $i$ is given by $y_{t}(i)=a_{t} n_{t}(i)$ where $a_{t}$ is the exogenous aggregate productivity level and $n_{t}(i)$ is the production labor used by firm $i$. The labor market is global so that all firms faced the same real marginal cost $w_{t} / a_{t}$, where $w_{t}$ is the aggregate real wage. Let $p_{j, t}$ be the relative price of firms that have not adjusted for $j$ period(s) at time $t$. Given the form of the CES consumption

\footnotetext{
${ }^{6}$ By end-of-period, I mean that these fractions are observed in the current period $t$ after firms' production and pricing decisions are made.

${ }^{7}$ As long as inflation is not zero and the support of the fixed cost distribution is finite, $J$ will be finite as well.

${ }^{8}$ The TDP specification is a generalization of two popular price/wage rigidity specifications. When $J \rightarrow \infty$ and $\alpha_{j}$ are identical across $j$, the specification collapses to Calvo (1983). For any finite $J$ and $\left\{\alpha_{j}\right\}_{j=1}^{J-1}=0$ with $\alpha_{J}=1$, we have the contracting model of Taylor (1980).
} 
aggregator above, it follows that the real profit of a firm with price $p_{j, t}$ is given by

$$
z\left(p_{j, t}, s_{t}\right)=\left[p_{j, t}-\frac{w_{t}}{a_{t}}\right] \cdot p_{j, t}^{-\varepsilon}\left(c_{t}+g_{t}\right) .
$$

Let's denote $v_{0}\left(s_{t}\right)$ as the value function of a typical adjusting firm, gross of the adjustment cost. Given the state vector $s_{t}$, the maximization problem of a typical adjusting firm is

$$
\begin{aligned}
v_{0}\left(s_{t}\right)= & \max _{p_{0}, t}\left\{z\left(p_{0, t}, s_{t}\right)+\beta E_{t} \frac{\lambda_{t+1}}{\lambda_{t}}\left(1-\alpha_{1, t+1}\right) v_{1}\left(p_{1, t+1}, s_{t+1}\right)\right. \\
& \left.+\beta E_{t} \frac{\lambda_{t+1}}{\lambda_{t}} \alpha_{1, t+1} v_{0}\left(s_{t+1}\right)-\beta E_{t} \frac{\lambda_{t+1}}{\lambda_{t}} \alpha_{1, t+1} w_{t+1} \Xi_{1, t+1}\right\}
\end{aligned}
$$

where the choice variable $p_{0, t}$ is the optimal relative price. The above expression says that an adjusting firm chooses the optimal price to maximize its expected present discounted values of current and future profits. In doing so, it has to take into account the possibility of price adjustment in future periods. There is an expected probability of $\left(1-\alpha_{1, t+1}\right)$ that it will choose not to adjust so that its expected value in the next period is $v_{1}\left(p_{1, t+1}, s_{t+1}\right)$. With expected probability $\alpha_{1, t+1}$, it will optimally choose to adjust so that its value becomes $v_{0}\left(s_{t+1}\right)$. The last term in the second line of (3) reflects the fact that if the firm decides to adjust in the next period, it must also pay the fixed adjustment cost. In the Bellman equation above, $\Xi_{1, t+1}$ is the expected fixed adjustment cost in the future period, conditional on adjustment. Since the fixed costs are in terms of labor unit, the expected cost in consumption units is then given by $w_{t+1} \Xi_{1, t+1}$. Note that since households own the firms, future periods are discounted by the effective discount factor $\beta E_{t} \frac{\lambda_{t+1}}{\lambda_{t}}$, where $\lambda_{t}$ is the shadow value of households' income.

For firms that do not adjust $(j=1, \ldots, J-1)$ and hence simply apply prices from the previous period, the value functions can be expressed $\operatorname{as}^{9}$

$$
\begin{aligned}
v_{j}\left(p_{j, t}, s_{t}\right)= & z\left(p_{j, t}, s_{t}\right)+\beta E_{t} \frac{\lambda_{t+1}}{\lambda_{t}}\left(1-\alpha_{j+1, t+1}\right) v_{j+1}\left(p_{j+1, t+1}, s_{t+1}\right) \\
& +\beta E_{t} \frac{\lambda_{t+1}}{\lambda_{t}} \alpha_{j+1, t+1} v_{0}\left(s_{t+1}\right)-\beta E_{t} \frac{\lambda_{t+1}}{\lambda_{t}} \alpha_{j+1, t+1} w_{t+1} \Xi_{j+1, t+1} .
\end{aligned}
$$

The first order necessary condition of the the dynamic problem (3) and recursive differentiation of (4) lead to a formula for the optimal nominal price,

$$
P_{0, t}=p_{0, t} \cdot P_{t}=\frac{\varepsilon}{\varepsilon-1} \frac{\sum_{j=0}^{J-1} \beta^{j} E_{t} \frac{\omega_{j, t+j}}{\omega_{0, t}} \frac{\lambda_{t+j}}{\lambda_{t}} \frac{W_{t+j}}{a_{t+1}}\left(P_{t+j}\right)^{\varepsilon} y_{t+j}}{\sum_{j=0}^{J-1} \beta^{j} E_{t} \frac{\omega_{j, t+j}}{\omega_{0, t}} \frac{\lambda_{t+j}}{\lambda_{t}}\left(P_{t+j}\right)^{\varepsilon-1} y_{t+j}},
$$

\footnotetext{
${ }^{9}$ There is no max operator in this expression since the only decision made by non-adjusting firms is the input decision for production to meet demand.
} 
where $P_{t}$ and $W_{t}$ are the aggregate price level (index) and nominal wage at time $t$, respectively. The CES aggregator implies the aggregate price index is given by

$$
P_{t}=\left[\int_{0}^{1} P_{t}(i)^{1-\varepsilon}\right]^{\frac{1}{1-\varepsilon}}
$$

The expression $\left(\omega_{j, t+j} / \omega_{0, t}\right)=\left(1-\alpha_{j, t+j}\right) \cdot\left(1-\alpha_{j-1, t+j-1}\right) \cdot \ldots \cdot\left(1-\alpha_{1, t+1}\right)$ in the optimal price equation is the expected probability of keeping the price constant (non adjustment) from time $t$ until time $t+j$. Equation (5) is similar in many respects to the optimal nominal price expression under the familiar time-dependent Calvo pricing. In such a setup, $\left(\omega_{j, t+j} / \omega_{0, t}\right)$ is constant but it still reflects the probability of non adjustment for $j$ periods. In the current SDP specification, this term is time-varying and thus serves as a time-varying effect on the discount factor. The optimal price thus depends on current and expected future demands, price levels, marginal costs, and probabilities of non adjustment. In a special case where the price level, the adjustment probability, and the marginal cost are expected to be constant, the optimal nominal price is simply a constant markup over current nominal marginal cost $\left(P_{0, t}=(\varepsilon /(\varepsilon-1)) \cdot\left(W_{t} / a_{t}\right)\right)$, as in the flexible-price solution.

On the equilibrium determination of the probability of adjustment, firms only adjust if there is a positive benefit of doing so; that is, if the value of adjustment outweighs the fixed cost associated with adjustment. Given the continuous distribution of the fixed adjustment cost, there will be a mass of firms at the margin for each $j$ that are indifferent between adjusting or keeping the price from the previous period. For these firms, there is a zero benefit to adjust, so that $\left(v_{0, t}-v_{j, t}\right)=w_{t} \bar{\epsilon}_{j, t}$, where $\bar{\epsilon}_{j, t}$ is the fixed cost at the margin for bin $j .{ }^{10}$ Hence, the proportion or probability of firms adjusting for each $j$ is given by

$$
\alpha_{j, t}=G\left(\frac{v_{0, t}-v_{j, t}}{w_{t}}\right)
$$

for $j=1, \ldots, J-1$. For $j=J$, we have $\alpha_{J, t}=1$ since all firms will find it optimal to adjust after $J$ periods. Finally, the average or expected adjustment cost conditional on adjustment is given by

$$
\Xi_{j, t}=\frac{1}{\alpha_{j, t}} \int_{0}^{G^{-1}\left(\alpha_{j, t}\right)} x d G(x)
$$

for $j=1, \ldots, J$. This concludes the description of the decisions faced by intermediate-good firms.

As a preview of the optimal monetary approach used in this paper, all the efficiency conditions of the firms' problem above become relevant constraints that must be respected by the committed

\footnotetext{
${ }^{10}$ This fixed cost at the margin is the largest cost that is actually paid by adjusting firms.
} 
monetary authority. Specifically, the monetary authority must respect the optimal price decisions by adjusting firms given by equation (5). ${ }^{11}$ It must also respect the firms' adjustment decision, which are summarized by (3) and (6). The evolution of the distribution of firms in (1) and (2) must also be respected. In particular, note that some of these constraints are forward-looking, which is why there needs to be a commitment mechanism in the optimal policy problem. This commitment mechanism is summarized by the lagged policy multipliers in a recursive Lagrangian problem, as will be made clear shortly.

\subsubsection{Households}

I turn next to the households' optimization problem. Since most elements of the households' optimization problem are identical to those in Khan, King, and Wolman (2003), I simply mention the core assumptions and proceed directly to the resulting efficiency conditions. Appendix A provides additional detail on the households' optimization problem.

Households choose the amount of final goods consumption $\left(c_{t}\right)$ and leisure $\left(l_{t}\right)$ to maximize a lifetime utility function subject to a budget constraint. The instantaneous utility function is assumed to be given by $u\left(c_{t}, l_{t}\right)=\frac{1}{1-\sigma} c_{t}^{1-\sigma}+\chi_{\frac{1}{1-\phi}} l_{t}^{1-\phi}$. Here, $\sigma$ is the inverse elasticity of intertemporal substitution and the parameter $\phi$ governs the labor supply elasticity. Final consumption goods can be purchased using credit or money (cash). Specifically, households choose to purchase a fraction of goods $\xi_{t}$ with credit and the balance $1-\xi_{t}$ with money. There is a cost associated with using credit, as in Baumol (1954) and Tobin (1956). ${ }^{12}$ These transaction time costs of using credit (in terms of labor time units) are heterogenous across goods and are randomly drawn from a continuous distribution with cumulative distribution function (CDF) $F($.). Since using credit is costly, money can be used to facilitate the purchase of final consumption goods. However, there is an opportunity cost to using money since households can purchase one-period discount bonds and obtain a return of $R_{t}$ (the nominal interest rate). Households thus must balance the costs associated with holding cash and using credit in purchasing final consumption goods. In the absence of costly credit (transaction time), households would purchase all goods using credit, as in the cashless model of Woodford (2003). At the other extreme where no credit is allowed, we have a familiar cash-in-advance model

\footnotetext{
${ }^{11}$ In terms of actual computation of the optimal policy, equation (5) must be written in a recursive form. This can be done by reformulating this constraint using the marginal value recursions, meaning the derivatives of the value functions (3) and (4) with respect to the optimal relative price $p_{0, t}$.

${ }^{12}$ Baumol (1954) and Tobin (1956) analyze the transaction cost model in a partial equilibrium setting. For applications in a general equilibrium setting, see e.g. Prescott (1987) and Dotsey and Ireland (1996).
} 
as in Lucas (1980). Finally, households also derive income from their labor effort in the amount of $w_{t} n_{t}$.

Proceeding to households' efficiency conditions, the labor-leisure optimal choice implies the equality between the utility cost of foregone leisure and the value of income gained by working; thus,

$$
u_{l}\left(c_{t}, l_{t}\right)=w_{t} \lambda_{t}
$$

The holdings of one-period nominal discount bonds require that

$$
\frac{\lambda_{t}}{1+R_{t}}=\beta E_{t} \frac{\lambda_{t+1}}{1+\pi_{t+1}}
$$

where $\pi_{t}$ is the net inflation rate. Next, the marginal utility of consumption must equal to the full price of a unit of final consumption good,

$$
u_{c}\left(c_{t}, l_{t}\right)=\lambda_{t}\left(1+R_{t}\left(1-\xi_{t}\right)\right) .
$$

Note that since there is an opportunity cost of using money, the full consumption price above involves the nominal interest rate $R_{t}$, multiplied by the fraction of goods bought using money, $\left(1-\xi_{t}\right)$. In the cashless version of the model, the condition is simply $u_{c}\left(c_{t}, l_{t}\right)=\lambda_{t}$.

The largest credit time cost that the representative household will choose to pay is $R_{t} c_{t} / w_{t}$ so that the fraction of goods purchased using credit is given by

$$
\xi_{t}=F\left(\frac{R_{t} c_{t}}{w_{t}}\right)
$$

where $F(\cdot)$ is the CDF of the distribution of time costs of credit use. Finally, the time use constraint for the economy is given by

$$
l_{t}+n_{t}+\int_{0}^{\left(R_{t} c_{t} / w_{t}\right)} x d F(x)=1
$$

where $\int_{0}^{\left(R_{t} c_{t} / w_{t}\right)} x d F(x)$ is the aggregate time costs of credit. Note that given $\xi_{t}$, the real money demand in the economy at any period $t$ is then $m_{t}=\left(1-\xi_{t}\right) c_{t}$. Appendix B provides more details on the money demand function, along with the credit cost distribution. ${ }^{13}$

\footnotetext{
${ }^{13}$ In addition to being more realistic, the inclusion of a monetary sector in the model is required from a technical standpoint. Note that without a monetary sector, the optimal steady-state inflation is zero. But the SDP model of Dotsey, King, and Wolman (1999) used here requires a non-zero steady state inflation rate. If inflation rate is zero, all firms would then optimally choose not to adjust forever in the steady state, so that $J \rightarrow \infty$. Hence, computing optimal policy under SDP here is not possible (without additional restrictions or assumptions) in a cashless model such as Woodford (2003).
} 


\subsubsection{Other equilibrium conditions and the state vectors}

To complete the model, there are several aggregate equilibrium conditions that need to be satisfied. First, the aggregate production of goods must be equal to the aggregate demand:

$$
a_{t} n_{t}^{y}=\left[\sum_{j=0}^{J-1} \omega_{j, t} p_{j, t}^{-\varepsilon}\right]\left(c_{t}+g_{t}\right)
$$

where $n_{t}^{y}$ represents the total labor used in production. Since the fixed adjustment costs are in term of labor costs, there is also the aggregate labor used for this price adjustment process given by

$$
n_{t}^{p}=\sum_{j=0}^{J-1} \omega_{j, t-1}\left(\alpha_{j+1, t} \Xi_{j+1, t}\right)
$$

The sum of the aggregate production labor and pricing labor must be equal to the total labor supply so that we have

$$
n_{t}^{y}+n_{t}^{p}=n_{t}
$$

Next, the relative price aggregation implied by the CES aggregator is given by

$$
\sum_{j=0}^{J-1} \omega_{j, t} p_{j, t}^{1-\varepsilon}=1
$$

Given the gross inflation $\left(1+\pi_{t}\right)$, the evolution of predetermined relative prices $($ for $j=1, \ldots, J-1)$ can be expressed by ${ }^{14}$

$$
p_{j t}=p_{j-1, t-1} \frac{1}{1+\pi_{t}} .
$$

Together with the lagged fractions of firms, $\left\{\omega_{j, t-1}\right\}_{j=0}^{J-1}$, the lagged relative prices, $\left\{p_{j, t-1}\right\}_{j=0}^{J-2}$, are elements of the endogenous state vector $k_{t}$ in $s_{t}^{1}$.

Finally, I assume simple driving processes for the exogenous variables (productivity and government purchases),

$$
\begin{aligned}
& \log \left(a_{t}\right)=\rho_{a} \log \left(a_{t-1}\right)+\sigma_{a} e_{z, t} \\
& \log \left(g_{t}\right)=\rho_{g} \log \left(g_{t-1}\right)+\sigma_{g} e_{g, t},
\end{aligned}
$$

where $\left[e_{z, t}, e_{g, t}\right] \in \eta_{t}$ are i.i.d. shocks, normalized to have unit variance. Here, $\sigma_{a}$ and $\sigma_{g}$ are the standard deviations of productivity and government purchase shocks, respectively. The exogenous state vector $\varsigma_{t}$ thus consists of $a_{t}$ and $g_{t}$. This completes the definition for the state vector $s_{t}^{1}$.

\footnotetext{
${ }^{14}$ Specifically, suppose that $P_{j-1, t-1}$ is the nominal price of the intermediate-goods for firms that have not adjusted their prices for $j-1$ periods at time $t-1$, with $j \leq J-1$. If a firm in this bin chooses not to adjust at time $t$, then $P_{j, t}=P_{j-1, t-1}$, so that $P_{j, t} / P_{t}=P_{j-1, t-1} / P_{t} \Rightarrow p_{j, t}=\left(P_{j-1, t-1} / P_{t-1}\right)\left(P_{t-1} / P_{t}\right) \Rightarrow p_{j, t}=p_{j-1, t-1} \frac{1}{1+\pi_{t}}$.
} 


\subsection{Identifying the four sets of distortions}

As mentioned previously, monetary policy influences various distortions in the economy; hence it is useful to explicitly identify these distortions. There are four sets of distortions present in the model economy. One can view these distortions as inefficiencies that exist in the economy. ${ }^{15}$

First, there is a distortion due to firms' monopoly power that is frequently termed the markup distortion and is captured by the reciprocal of the real marginal cost,

$$
\psi_{t}=\frac{a_{t}}{w_{t}} .
$$

If firms are perfectly competitive as in a standard real business cycle (henceforth, RBC) model, $\psi_{t}=1$ since the real wage is always equal to productivity. This distortion influences, for example, the firms' value functions (3), (4) and the optimal price chosen by adjusting firms (5).

Second, there is a distortion arising from infrequent price adjustments (sticky prices), frequently termed the relative-price distortion ${ }^{16}$

$$
\Delta_{t}=\frac{a_{t} n_{t}^{y}}{\left(c_{t}+g_{t}\right)}=\sum_{j=0}^{J-1} \omega_{j, t} p_{j, t}^{-\varepsilon}
$$

This distortion measures the extent of lost aggregate output due to sticky prices - if $\Delta_{t}$ is greater than unity, then it takes more labor to produce a given volume of output as suggested by (13). Both the markup and relative-price distortions are eliminated at zero inflation where both $\psi_{t}$ and $\Delta_{t}$ are equal to unity. The model then collapses to a standard RBC framework if monetary frictions are absent.

The third set of distortions involve the use of money and credit in purchasing consumption goods. Frequently termed the monetary distortions, these distortions can be decomposed further into the monetary wedge and shopping-time distortions. The monetary wedge distortion is the inefficiency that arises because the full cost of consumption is augmented by the requirement that money must be held to finance a portion of consumption purchase. It can be expressed as

$$
\Phi_{t}=R_{t}\left(1-\xi_{t}\right)
$$

As suggested by (10), this distortion drives a wedge between the marginal utility of consumption and the shadow value of wealth. ${ }^{17}$ The shopping-time distortion arises because the use of credit in

\footnotetext{
${ }^{15}$ Although I choose not to pursue it here, it is possible to eliminate these distortions through the use of fiscal subsidies, as in Woodford (2002) and Levin et.al. (2005).

${ }^{16}$ This relative-price distortion is already widely identified in various studies in the literature, such as Damjanovic and Nolan (2006) King and Wolman (1999), and Yun (2008).

${ }^{17}$ This monetary-wedge distortion is highlighted in cash-in-advance models, for instance, Cooley and Hansen (1991) and Stockman (1981).
} 
purchasing consumption goods requires some use of labor; this distortion affects the total available resources in (12). It is governed by the expression

$$
h_{t}=\int_{0}^{\left(R_{t} c_{t} / w_{t}\right)} x d F(x) .
$$

Both the monetary wedge and the shopping-time distortions are minimized at zero nominal interest rate as prescribed by the Friedman rule, so that the inflation rate must be negative (deflation).

In the time-dependent-pricing version of the model, all three distortions mentioned above are present. Under SDP, there exists another distortion involving the costs associated with price adjustments, represented by (14):

$$
n_{t}^{p}=\sum_{j=0}^{J-1} \omega_{j, t-1}\left(\alpha_{j+1, t} \Xi_{j+1, t}\right)
$$

Like the shopping-time distortion, this menu cost distortion can be viewed as a drain on the economy's resources.

To gain more insight into the distortions, Figure 1 looks at the steady-state implications of these various inefficiencies in the model economy. First, we look at the relationship between inflation and the relative price distortion in panels A and B. For simplicity and comparability to the literature, these two panels are produced under the assumptions that there are no monetary distortions and firms' pricing decisions are time-dependent. ${ }^{18}$ Looking first at panel A, the optimal relative price $\left(p_{0}\right)$ is equal to 1 (one) under zero inflation and is increasing with inflation. When inflation is positive, price-adjusting firms will charge a higher price since they anticipate that the relative price will be eroded by future inflation. On the contrary, under negative inflation (deflationary steady state), the optimal relative price is lower since the relative price will increase if firms do not adjust in future periods. That is, those firms which do not adjust will be faced with a decreasing relative price under positive inflation and an increasing relative price under deflation - as a consequence, price dispersion is increasing with both non zero inflation and deflation (panel B). Only under zero inflation is the relative price distortion is eliminated and a unit of labor will exactly produce a unit of output. Panel C looks at the implication of varying degrees of average markup on market activity (production labor). As the average markup increases, there is a corresponding decrease in the real wage paid by firms so that households substitute away from market activity. As we

\footnotetext{
${ }^{18}$ Specifically, I assume that $J=6$, with $\left\{\omega_{j}\right\}_{j=0}^{J-1}$ and $\left\{\alpha_{j}\right\}_{j=1}^{J-1}$ equal to their steady-state values under the optimal policy presented in figure 2. For any given inflation rate, we can compute the optimal reset price and the corresponding relative price distortion at the steady state. Assuming state dependence does not change the figures in panels $\mathrm{A}$ and $\mathrm{B}$.
} 
will see in a later section, the monetary authority can temporarily erode this average markup by generating surprise inflation.

Moving on to the monetary distortions in the right-side panels of Figure 1, we see that households substitute away from cash transactions into costly credit since the opportunity cost of holding money becomes higher as the nominal interest rate increases. ${ }^{19}$ As a consequence, the fraction of goods bought using credit increases with the nominal rate (panel D). Higher nominal rates are also associated with higher monetary wedge distortions (panel E), which in turn create a substitution away from consumption since this wedge affects the full cost of consumption as shown in equation (10). Finally, as displayed in panel E, the higher fraction of credit goods associated with higher nominal rates will in turn increase the transaction (shopping) time associated with costly credit.

Figure 1 also shows that there is a tradeoff among the distortions, even in this simple static illustration. As an illustration, we know from panel B that the relative price distortion is minimized at zero steady-state inflation. However, at zero inflation, the nominal interest rate must be positive for the Fisher equation (9) to be satisfied-hence, the monetary wedge distortion (panel E) is not minimized. On the contrary, if the nominal interest rate is zero so that there is a small deflation at the steady state, the relative price distortion will not be minimized. The task of the monetary authority then is to balance the costs of these various distortions, both in the steady state and in the near-steady-state dynamics in response to any exogenous shock.

\subsection{Optimal monetary policy: approach and methodology}

\subsubsection{The optimal policy approach}

Several private sector efficiency conditions described above involve forward-looking constraints and are defined recursively. As such, I use the recursive optimal policy design approach along the lines of Kydland and Prescott (1980) and Marcet and Marimon (1999). I present this approach briefly below, where a complete and formal treatment can be found in Johnston, King, and Lie (2008). This optimal policy approach is similar to that used, for example, in Schmitt-Grohe and Uribe (2007). Yet, as shown in Rotemberg and Woodford (1999) and Woodford (2002) in the case of undistorted steady state and Benigno and Woodford $(2004,2008)$ in the more general case of

\footnotetext{
${ }^{19}$ To generate panels $\mathrm{D}, \mathrm{E}$, and F, I assume that the credit cost distribution is Beta with the parameters as in table 1. I also assume that the production labor is $n^{y}=0.2$, and the real wage $w=a=1$, with consumption $c=a \cdot n^{y}=0.2$. For any given nominal interest $R$, we can then compute the credit good fraction $\xi$ and the two monetary distortions.
} 
distorted steady state, the optimal policy problem described below can be also presented in a linearquadratic (LQ) framework. That is, under some regularity conditions, one can derive a quadratic loss function using the second-order approximation to the lifetime utility function. The problem of the monetary authority is then to minimize this loss function with the constraints being the linear approximations to the private sector efficiency conditions, which usually result in an aggregate supply equation (the Phillips curve) and an aggregate demand equation (the IS curve). In addition to having to derive such a loss function, which is not a trivial task itself, a drawback of this approach is that the resulting policy reaction function is linear. The optimal policy problem presented below allows an implied policy reaction function that is nonlinear if the equilibrium equations of the model are approximated to the second order or higher. Hence, it allows for a richer analysis, especially if one is interested in analyzing the degree of nonlinearity and state-dependence in the model and in the policy rule. ${ }^{20}$

The benevolent policy authority is concerned with the maximization of the present value expression

$$
E_{t}\left\{\sum_{j=0}^{\infty} \beta^{j} U\left(b_{t+j}, k_{t+j}, x\left(\varsigma_{t+j}\right)\right)\right\}
$$

via suitable choices of control variables, $b_{t}$, and is subject to constraint sets

$$
\begin{gathered}
\psi\left(b_{t}, k_{t}, x\left(\varsigma_{t}\right)\right) \geq 0 \\
g^{1}\left(b_{t}, k_{t}, x\left(\varsigma_{t}\right)\right)+\beta E_{t} g^{2}\left(b_{t+1}, k_{t+1}, x\left(\varsigma_{t+1}\right)\right) \geq 0,
\end{gathered}
$$

where $k_{t}$ and $\varsigma_{t}$ are vectors of endogenous and exogenous state variables, respectively. The processes for these state vectors are given by

$$
\begin{gathered}
\varsigma_{t+1}=\nu\left(\varsigma_{t}, \eta_{t+1}\right) \\
k_{t+1}=\kappa\left(b_{t}, k_{t}, x\left(\varsigma_{t}\right), x\left(\varsigma_{t+1}\right)\right) .
\end{gathered}
$$

Note that I only present the case where the forward-looking constraints involve one-period ahead in time, but it is possible to generalize this set to include forward-looking constraints that stretch to infinity as shown in Marcet and Marimon (1999). One can then form a standard Lagrangian problem with (24), (25), (26), and (27) as the full constraint sets.

\footnotetext{
${ }^{20}$ Note that this section on the optimal policy approach has a separate notation than the rest of the paper, as it only serves to present the general methodological approach.
} 
Following Marcet and Marimon (1999), the set of forward-looking constraints can be handled with a generalization of Bellman equation of the form

$$
W\left(\mu_{t}, k_{t}, \varsigma_{t}\right)=\min _{\gamma_{t}} \max _{b_{t}}\left\{h\left(b_{t}, \gamma_{t}, \mu_{t}, k_{t}, x\left(\varsigma_{t}\right)\right)+\beta E W\left(\mu_{t+1}, k_{t+1}, \varsigma_{t+1}\right) \mid\left(\mu_{t}, k_{t}, \varsigma_{t}\right)\right\}
$$

where the evolution of the pseudo state vector, $\mu_{t}$, is given by

$$
\mu_{t+1}=\gamma_{t}
$$

Here, $\gamma_{t}$ is the vector of current (time $t$ ) multipliers associated with the forward-looking constraints (25) and $\mu_{t}$ is the vector of the lags of these multipliers. One can view these lagged multipliers as explicit commitment technologies. Note that in the Bellman equation above the modified objective function takes the form

$$
\begin{aligned}
h\left(b_{t}, \gamma_{t}, \mu_{t}, k_{t}, x\left(\varsigma_{t}\right)\right)= & u\left(b_{t}, k_{t}, x\left(\varsigma_{t}\right)\right) \\
& +\gamma_{t} g^{1}\left(b_{t}, k_{t}, x\left(\varsigma_{t}\right)\right) \\
& +\mu_{t} g^{2}\left(b_{t}, k_{t}, x\left(\varsigma_{t}\right)\right) .
\end{aligned}
$$

Further, the modified objective function above can be augmented with the Lagrangian terms involving the point-in-time constraint sets in (24) yielding $p_{t} \psi\left(b_{t}, k_{t}, x\left(\varsigma_{t}\right)\right)$, where $p_{t}$ is the vector of Lagrange multipliers associated with these constraints. We can thus focus our attention on the composite expression

$$
\begin{aligned}
W\left(\mu_{t}, k_{t}, \varsigma_{t}\right)= & \min _{p_{t}, \gamma_{t}} \max _{b_{t}}\left\{w\left(b_{t}, p_{t}, \gamma_{t}, \mu_{t}, k_{t}, x\left(\varsigma_{t}\right)\right)\right. \\
& \left.+\beta E W\left(\mu_{t+1}, k_{t+1}, \varsigma_{t+1}\right) \mid\left(\mu_{t}, k_{t}, \varsigma_{t}\right)\right\},
\end{aligned}
$$

where the maximization-minimization problem is also subject to the state evolution equations in (26), (27), and (28) and the initial conditions on $\mu_{t}, k_{t}$, and $\varsigma_{t}$. In the above expression the function $w($.$) is h\left(b_{t}, \gamma_{t}, \mu_{t}, k_{t}, x\left(\varsigma_{t}\right)\right)+p_{t} \psi\left(b_{t}, k_{t}, x\left(\varsigma_{t}\right)\right)$. The results of solving this problem are the decision rules

$$
\begin{aligned}
& b_{t}=b\left(k_{t}, \varsigma_{t}, \mu_{t}\right) \\
& p_{t}=p\left(k_{t}, \varsigma_{t}, \mu_{t}\right) \\
& \gamma_{t}=\gamma\left(k_{t}, \varsigma_{t}, \mu_{t}\right),
\end{aligned}
$$


so that the state and pseudo-state vectors evolve according to

$$
\begin{aligned}
\varsigma_{t+1} & =\nu\left(\varsigma_{t}, \eta_{t+1}\right) \\
k_{t+1} & =\kappa\left(k_{t}, b\left(k_{t}, \varsigma_{t}, \mu_{t}\right), x\left(\varsigma_{t}\right), x\left(\varsigma_{t+1}\right)\right) \\
\mu_{t+1} & =\gamma\left(k_{t}, \varsigma_{t}, \mu_{t}\right) .
\end{aligned}
$$

\subsubsection{Application to the model economy}

The optimal policy approach described above can be readily applied to solve for the optimal precommitment policy that is the subject of this paper. The objective function of the monetary policy authority is simply the households' lifetime utility function in our model economy. Each of the private sector constraints described previously fits into either the constraint set in (24) or (25) and the evolution of the state vectors $s_{t}^{1}$ fall into the restrictions described in (26) and (27). For example, (6), (8), (10), and (13) are parts of the point-in-time constraint sets (24), while (3), (4), and (9) are forward-looking constraints as identified in (25). The evolution of the fractions of firms in (1) and predetermined prices in (17) would fit into the evolution equation described in (27). In terms of vectors of variables, consumption $\left(c_{t}\right)$ and labor $\left(n_{t}\right)$ are parts of the control vector $b_{t}$, for example. The endogenous state vector $k_{t}$ would consist of the lagged predetermined relative prices, $\left\{p_{j, t-1}\right\}_{j=0}^{J-2}$ and the lagged fractions of firms, $\left\{\omega_{j, t-1}\right\}_{j=0}^{J-2}$. The vector $p_{t}$ includes the Lagrange multipliers attached to all of the point-in-time private sector constraints in the model. On the other hand, the multipliers associated with forward-looking constraints such as (9) are elements of the vector $\gamma_{t}$. The vector $\mu_{t}$ consists of lagged multipliers associated with forward-looking constraintsthis vector is thus the model's second set of state variables, $s_{t}^{2}$, described earlier. Recall that this vector of lagged multipliers summarizes the past policy plans or commitment that must be followed by the monetary authority. To solve for the optimal policy, we can form a saddle point functional equation as in (29) and take all the private-sector efficiency conditions as the policy constraints. The first-order conditions of this optimization problem would then represent the allocations under the optimal policy.

Recursive equilibrium The recursive equilibrium is defined as follows: given the state vector $s_{t}$, the evolution of the exogenous state variables, and the optimal precommitment policy rule employed by the monetary authority, both households and intermediate-good firms solve their optimization problems as described above. The market-clearing conditions for the goods and the labor markets, 
(13) and (15), are also satisfied in equilibrium. Finally, the optimal policy rule is consistent with and respects households' and firms' (the private sector's) efficiency conditions.

\subsubsection{Approximate solutions}

The model is solved using the perturbation approximation solution method of Johnston, King, and Lie (2009). Specifically, the first order necessary conditions of the optimal policy problem above can be written as a system of nonlinear equations in the expectational form

$$
E_{t} F\left(z_{t+1}, z_{t}, \eta_{t+1}\right)=0
$$

where $z_{t}$ is the vector of all variables (including both endogenous and exogenous variables) at time $t$ and $\eta_{t+1}$ is the vector of exogenous shocks at time $t+1$. Johnston, King, and Lie (2009) show that the solution to a second-order Taylor-series approximation to the above system can be cast into a nearly linear state-space representation of the form

$$
\begin{gathered}
z_{t} \simeq \underbrace{\left(z+\Pi_{1} d s_{t}\right)}_{1 s t}+\underbrace{\frac{1}{2} E d^{2} z_{t}+\frac{1}{2}\left[\begin{array}{ll}
\Pi_{1} & \Pi_{2}
\end{array}\right]\left[\begin{array}{c}
d^{2} s_{t}-E d^{2} s_{t} \\
\xi_{t}
\end{array}\right]}_{2 n d} \\
{\left[\begin{array}{c}
d s_{t+1} \\
d^{2} s_{t+1}-E d^{2} s_{t} \\
\xi_{t+1}
\end{array}\right]=\left[\begin{array}{ccc}
\delta & 0 & 0 \\
0 & \delta & \lambda \\
0 & 0 & \rho
\end{array}\right]\left[\begin{array}{c}
d s_{t} \\
d^{2} s_{t}-E d^{2} s_{t} \\
\xi_{t}
\end{array}\right]+\left[\begin{array}{cc}
\alpha & 0 \\
0 & \gamma_{\eta} \\
0 & \gamma_{e}
\end{array}\right]\left[\begin{array}{c}
\eta_{t+1} \\
e_{t+1}
\end{array}\right]}
\end{gathered}
$$

where the first equation is the observational output equation and the second equation represents the state evolution equation. Here $d^{j} x_{t}$ is the $j-t h$ differential of the vector of variables $x_{t}$, $\xi_{t}=d s_{t} d s_{t}^{T}-E\left(d s_{t} d s_{t}^{T}\right)$, and $e_{t+1} \equiv\left[\operatorname{vech}\left(\eta_{t+1} \eta_{t+1}^{T}-E\left(\eta_{t+1} \eta_{t+1}^{T}\right)\right)^{T} \operatorname{vec}\left(d s_{t} \eta_{t+1}^{T}\right)^{T}\right]^{T} \cdot{ }^{21} \Pi_{1}$, $\Pi_{2}, \delta, \lambda, \rho, \alpha, \gamma_{\eta}$, and $\gamma_{e}$ are matrices of coefficients. Also, $E d^{2} z_{t}$ and $E d^{2} s_{t}$ are the unconditional expectations of the second differential of the vector of endogenous and state variables, respectively. Note that this second-order state space form also encompasses the linear (first-order) approximate solution. That is, under a linear approximation, the output equation only contains the first bracketed term (1st) and the state evolution system in the second equation above only contains the first line $\left(d s_{t+1}=\delta d s_{t}+\alpha \eta_{t+1}\right)$.

\footnotetext{
${ }^{21}$ The supercript $^{T}$ is the transpose of a vector or a matrix. Here, vec(.) is the standard vectorization operation. For any symmetric matrix $A$, some of the elements of $\operatorname{vec}(A)$ are redundant. If we define $D_{m}$ as the unique duplication matrix for $A$ (see for instance, Magnus and Neudecker, 2002) that selects the unique (upper triangular) elements of $A$, so we can then define $\operatorname{vec}(A)=D_{m} \operatorname{vech}(A)$, where $\operatorname{vech}(A)$ now contains only unique elements of $\operatorname{vec}(A)$.
} 
Defining impulse response as the revision in forecast errors, $E_{t} z_{t+j}-E_{t-1} z_{t+j}$, one can apply the state-space form above recursively to calculate the response of the economy to any given shock for a given starting state. ${ }^{22}$ The analyses in the next section use this state-space form to generate various impulse responses. For later references, I will call the response based on the first-order approximate solution as the first-order impulse response, while the second-order impulse response refers to the response based on the second-order approximate solution.

Several comments on the second-order state-space form are in order. Compared to the firstorder, there are some additional terms in the exogenous shock vector in the second-order state-space form within (31). First, there is a $\operatorname{vech}\left(\eta_{t+1} \eta_{t+1}^{T}-\Omega_{\eta \eta}\right)$ term, where $\Omega_{\eta \eta}=E\left(\eta_{t+1} \eta_{t+1}^{T}\right)$ is the covariance matrix of the exogenous shocks-in the context of my model, $\Omega_{\eta \eta}=\left[\begin{array}{cccc}\sigma_{a}^{2} & 0 ; & 0 & \sigma_{g}^{2}\end{array}\right]$. This term in general captures the nonlinearity of the exogenous shocks if the shocks themselves enter nonlinearly in the model. Such a nonlinearity is not present in the first-order approximate solution. Even when shocks enter linearly in the model as in the current model, the effect of this term may not be zero. This is because this term is also related to the uncertainty of the shock process itself, meaning it is related to the "uncertainty correction" term in the jargon of the literature on secondorder approximation. ${ }^{23}$ This term then leads to asymmetric responses to different shock sizes. For example, in the first-order impulse response when shocks enter linearly, the response to a twostandard-deviation shock has the same property as the response to a one-standard-deviation shock. That is, if output increases by 1 percent in response to a one-standard-deviation productivity shock, a two-standard-deviation shock will increase output by 2 percent. A shock of a given magnitude is also symmetric irrespective of whether the shock is positive or negative: to the first-order, the response of a variable to an $m$ percent negative shock is just the opposite of the response to an $m$ percent positive shock. This symmetric property is unappealing for various reasons. For example, one might expect that the monetary authority or an optimizing agent might behave differently in response to an unfavorable shock compared to a favorable shock. Only in the second-order impulse response is this asymmetric property captured.

The second additional term is the state-dependent response to shocks. This state-dependence

\footnotetext{
${ }^{22}$ The method here is related to several recent contributions on second-order approximations such as SchmittGrohe and Uribe (2004), Lombardo and Sutherland (2007), and Kim, et. al. (2008). A main insight of Johnston, King, and Lie (2009) is that if one derives restrictions directly on the equilibrium equations of the model, rather than on the assumed policy function, the approximate solution will always be in a state-space form. Hence, no additional modification such as "pruning" in Kim, et. al. (2008) is necessary. Moreover, the state-space form is always achieved for any n-th order approximation.

${ }^{23}$ See for example, Schmitt-Grohe and Uribe (2004).
} 
property is captured in the second-order approximation through the term $\operatorname{vec}\left(d s_{t} \eta_{t+1}^{T}\right)$. That is, the economy's response to a shock depends nonlinearly on the state of the economy, which is an especially appealing property for state-dependent pricing models - the first-order impulse response does not capture this state-dependence effect. These two additional nonlinear terms can be particularly important, especially when the state of the economy is farther away than the certainty steady state.

\subsection{Calibration and the steady-state inflation under optimal policy}

Table 1 presents the calibration of the parameters in the model. The time unit is meant to be a quarter. The choice of $\sigma$ and $\phi$ equal unity means that the utility function involves log function in consumption and leisure. The parameter $\chi$ in the utility function is chosen such that the steadystate total labor is equal to 0.2 . The choice of demand elasticity $(\varepsilon=10)$ is a compromise among various studies that report various values for this parameter, for instance Altig et. al. (2005), Basu and Fernald (1997), and Rotemberg and Woodford (1999). This value implies that the markup is equal to about 11.11 percent in the flexible-price equilibrium.

In terms of the fixed adjustment cost distribution, I use a Beta distribution with left and the right parameters equal to $a_{l}=2.1$ and $a_{r}=1$, respectively. This implies a probability density function (PDF) that is strictly increasing and strictly convex. ${ }^{24}$ Appendix $\mathrm{C}$ provides more details on the specification of this adjustment cost distribution. I calibrate the largest possible fixed cost paid by firms, $B$, so that the maximum number of quarters of price fixity $(J)$ is 6 quarters. Figure 2 displays the steady-state probability $\left(\alpha_{j}\right)$ and firms' distribution $\left(\omega_{j}\right)$ of price adjustment based on these calibrated parameters under the optimal precommitment policy. This figure shows that the price adjustment hazard is increasing with the time since last price adjustment, unlike the constant hazard implied by the standard Calvo model. In addition, the figure implies that the mean and median durations of price fixity are 4.02 quarters and 3.00 quarters, respectively, and the average frequency of price adjustment is about 24 percent per quarter. This degree of price rigidity is in the ballpark of available empirical estimates using macroeconomic data such as Christiano, Eichenbaum, and Evans (2005). It is higher than the evidence based on microeconomic data reported in Bils and Klenow (2004), but still close to the finding in Nakamura and Steinsson

\footnotetext{
${ }^{24}$ I also experiment with various shape parameters of the Beta distribution that yield various shapes of the PDF: linear, strictly increasing, strictly convex, or combinations of these. Each time, similar results are found for both the steady-state and near steady-state dynamics analyzed in subsequent sections. Changing the distribution to the one used in Dotsey and King (2005) also preserves the paper's results.
} 
(2008).

The parameters of the credit cost distribution, which governs the demand for money, are set according to the estimation in Khan, King, and Wolman (2003). Appendix B describes the implied money demand function and elasticity based on their estimates. The rest of the parameters involve the exogenous driving processes. Following King and Rebelo (1999), the aggregate productivity is very persistent $\left(\rho_{a}=0.95\right)$, with the standard deviation $\left(\sigma_{a}\right)$ equal to 0.0072 . Finally, the choices of $\rho_{g}$ and $\sigma_{g}$ are in line with the estimates in Ravn (2007).

Optimal steady-state inflation I next consider the steady-state inflation under the optimal policy. Recall that the task of the benevolent monetary authority is to balance the costs of various distortions in the economy. As shown by various studies, e.g. King and Wolman (1999) and Woodford (2002), the optimal steady-state inflation is zero when only relative-price and markup distortions are present. That is, both of these distortions are eliminated under zero steady-state inflation and there is no long-run tradeoff between them. The presence of the menu cost distortion in the current SDP model does not alter this conclusion since this distortion is also eliminated under zero inflation. (Firms would find no need to change prices under zero inflation and hence would never have to pay the adjustment costs.) However, as shown by Khan, King, and Wolman (2003) and Schmitt-Grohe and Uribe (2007) in the TDP case, the presence of monetary distortions alters the tradeoff faced by the monetary authority. As prescribed by the Friedman rule, the distortions due to money demand are eliminated when the opportunity cost of holding money - the nominal interest rate - is zero. This requirement implies that inflation must be negative (deflation). It follows that the optimal steady-state inflation when all distortions are present (henceforth, "full" distortions) should also be negative, but not as negative as implied by the Friedman rule. Put another way, the monetary authority compromises between maintaining price stability and following the Friedman rule.

Table 2 shows that the optimal steady-state inflation rate in the SDP model reflects the above discussion. As expected, in the benchmark case with all the distortions present, the steady-state (net) inflation is negative ( -0.99 percent at the annualized rate under SDP) but not as negative as the Friedman rule $(-2.88$ percent with the calibrated discount rate $\beta)$. Under a lower elasticity of demand $(\varepsilon=7)$, the steady state deflation increases to -1.50 percent per annum. This higher deflation is associated with the lower cost of relative price distortion implied by the lower elasticity 
of demand. Next, when the variations in either the monetary wedge or the shopping-time distortion are eliminated, the steady state deflation is closer to zero since the relative-price, menu cost, and markup distortions, which are minimized at zero inflation, become relatively more important. ${ }^{25}$ Eliminating variations in the markup distortion leads to a larger steady-state deflation due to greater relative importance of the two monetary distortions. ${ }^{26}$

I next compare the optimal steady-state inflation under SDP and TDP. Note that the TDP model counterpart is constructed under the assumption that the parameters $\left\{\alpha_{j}\right\}_{j=1}^{J}$ and $\left\{\omega_{j}\right\}_{j=0}^{J-1}$ are equal to the steady-state values under the SDP model, with all other structural parameters remain the same as their counterparts under SDP. In the "full" distortions case, there is a slightly larger deflation rate (-0.988 percent) under TDP than under SDP (-0.992 percent). This pattern is also apparent under lower $\varepsilon$ or when one or more sets of distortions are eliminated. This can be understood as follows. First, even though in the TDP model we have the same adjustment patterns $\left(\alpha_{j}\right.$ and $\left.\omega_{j}\right)$ as in the steady state under SDP, the steady state allocation under SDP is not the equilibrium allocation under TDP. This is because there are "freed" resources in terms of labor/leisure time under TDP since firms do not have to pay the adjustment costs. These unused resources would be optimally dispersed as additional leisure or labor time. Since this additional labor time can be used to produce more output, the economy under TDP would be producing more efficiently (closer to potential) with lower average markup distortions than the economy under SDP. Since a lower steady state markup is associated with smaller deflation (inflation is closer to zero), it follows that the optimal steady-state deflation rate should be smaller under TDP than under SDP. However, the difference is quite small since these extra resources from price adjustment activity under SDP are also small. ${ }^{27}$ This result also means that if firms under TDP were also required to pay the same amount of fixed costs when they adjust as in the SDP case, the optimal steady-state inflation should be identical under the two cases. This is as expected since both cases are calibrated under identical steady-state frequency of price adjustment, meaning $\alpha_{j}$ and $\omega_{j}$ are identical in the

\footnotetext{
${ }^{25}$ By eliminating variations in distortions, we mean that we make it impossible for the monetary authority to influence or manipulate the variations in the distortions. This can be thought using the idea of fiscal subsidy: government would provide subsidy when there are movements in distortions so that these distortions would always be equal to a certain level. In terms of the model specific, for example when we want to remove variations in the monetary-wedge distortion, we then set $R(1-\xi)$ in (10) to a certain constant level and resolve the model. At least one of the distortions have to be present in the economy-otherwise, there is no scope for stabilization policy.

${ }^{26}$ Here, the (constant) markup is set to equal to the steady-state markup under optimal policy with all the distortions present.

${ }^{27}$ Specifically, the aggregate labor resources used in price adjustment activities in the steady state is about 0.016 percent of aggregate steady-state total labor.
} 
steady state for all $j$.

\section{Optimal timeless perspective (long-run) responses}

\subsection{Productivity shock}

This section considers the first-order optimal responses to a temporary productivity shock under the assumption of timeless perspective (Woodford, 2003). That is, although the true Ramsey solution involves a monetary authority that treats initial periods differently due to the absence of past commitments, we assume that the monetary authority ignores this "start-up problem." Put another way, the monetary authority is assumed to have committed to the state-contingent policy rule since time immemorial. The cost of ignoring these initial conditions is analyzed in section 5 .

Throughout the analysis below the economy is assumed to be always at the steady state prior to the shock and the shock size is 2 (two) standard deviations, normalized so that productivity increases by 1 percent on impact relative to its steady state value.

RBC and TDP without monetary distortions I begin the analysis with a review of the optimal monetary policy response in the time-dependent pricing (TDP) model with only relativeprice and markup distortions, as in Benigno and Woodford (2005), Goodfriend and King (1997), King and Wolman (1999), and Woodford (2002). The response in a familiar simple real business cycle (RBC) model is calculated and displayed as well to serve as a benchmark. ${ }^{28}$ Both the RBC model and the "cashless" TDP model share the same zero steady-state inflation.

The optimal response to a productivity shock in this cashless TDP model is to exactly replicate the allocation in the RBC environment, albeit in a monopolistically competitive setting (Figure 3). Here, it is optimal to keep inflation at its zero steady-state level and to fully accomodate the productivity shock. That is, price stability in response to a productivity shock is optimal when monetary distortions are absent. Consumption increases one-to-one (1 percent on impact) with the shock throughout the whole period of higher productivity. Labor is essentially constant: there is an exact offset of wealth and substitution effects reflecting the households' preference specification. ${ }^{29}$

\footnotetext{
${ }^{28}$ To permit direct comparison with the TDP model, the firms in the RBC model also use labor as the only input in production, hence we abstract from capital accumulation. Prices are flexible and firms are assumed to be monopolistically competitive.

${ }^{29}$ Labor in this figure and subsequent ones only include the dynamics of labor used in production. The dynamics of production labor are virtually identical to the dynamics of total labor since labor used in costly credit transaction and in price adjustment activity (under SDP) are small, both in the steady state and in the near steady-state dynamics.
} 
Since inflation remains equal to its zero steady-state level, the average markup and relative price distortions continue to be minimized and hence there are zero variations in each of these distortions (not shown). Regarding the interest rate's movements, initially there is a decrease in the real rate when consumption is high relative to the steady state, but it grows over time to its steady-state level as consumption is expected to decrease to its steady-state level. Since inflation is zero, the nominal rate and real rate responses exactly coincide.

This complete price stability result is in accord with that obtained in a linear-quadratic (LQ) framework such as Clarida, Galí, and Gertler (1999) and Benigno and Woodford (2005). In an LQ framework, the loss function in this two-distortion case is a quadratic function of inflation and an output gap measure. As stressed by Benigno and Woodford (2005) among others, in the isoelastic utility case under zero steady-state government purchase, there is no tradeoff between inflation and output gap stabilizations in response to a productivity shock. Minimizing inflation variation also minimizes the variation in the output gap.

TDP with and without monetary distortions Figure 4 compares the optimal responses under TDP with and without monetary distortions. ${ }^{30}$ The presence of additional frictions from money demand alters the tradeoff faced by the monetary authority. In addition to the costs of variations in the relative-price and markup distortions, the monetary authority also needs to manage the cost of variations in the nominal interest rate that affects the opportunity cost of holding money. As shown in Figure 4, complete inflation stabilization is no longer optimal, though feasible, in such an environment. The monetary authority in this environment has to compromise between complete price stability and the Friedman rule.

One can see this compromise from the responses of inflation and the nominal interest rate in Figure 4. First, it is no longer optimal for inflation to stay constant since we know from Figure 3 that the nominal rate has to decrease by a bit more to be consistent with constant inflation. Hence, in such a scenario, the monetary authority completely ignores the welfare cost of nominal interest rate movements. On the other hand, if the nominal rate is completely stabilized as in the Friedman rule, inflation has to vary by more to accomodate movements in the real interest rate associated with consumption movements. Under the optimal policy, the compromise means that

\footnotetext{
${ }^{30}$ The case considered here with monetary distortions is identical to the model in Khan, King, and Wolman (2003), with the exception of the difference in calibration of the firms' distribution parameters $\left\{\omega_{j}\right\}_{j=0}^{J-1}$. Johnston, King, and Lie (2008) instead consider Calvo (1983) price setting but with the same four distortions. Both studies display largely similar dynamics as those presented here.
} 
the nominal rate responses are smoothed out relative to the case where monetary distortions are absent. Inflation is no longer constant: there is a slight deflation on impact but inflation is higher relative to the steady state in subsequent periods. The inflation and nominal rate responses imply that consumption increases by a bit less than 1 percent before subsequently tracking productivity.

Despite the differences in the dynamics between the TDP case with and without monetary frictions, the optimal policy here can still be considered as an "approximate price stability" rule in a sense the price level remains largely stabilized. For example, the largest deviation of inflation is only about 5 basis points deviation (0.05 percent) at the annual rate. Using a medium-scale macroeconomic model that accords well with postwar U.S. business cycles, Schmitt-Grohe and Uribe (2007) report the same conclusion regarding this approximate price stability result.

TDP and SDP with "full" distortions Finally, Figure 5 compares the long-run timeless perspective responses under the TDP and SDP models when all four sets of distortions are present. The optimal response under SDP is to closely replicate the dynamics under the TDP model counterpart, indicating that approximate price stability is also optimal. It is again optimal to have a slight deflation on impact in response to a productivity shock, although the inflation variation is larger under SDP. However, inflation response is again muted: the largest deviation of inflation is less than an 8-basis-point deviation from the steady-state value (in quarter three). The monetary authority also smooths out the nominal interest rate movements due to the presence of the monetary distortions. As in the TDP case, consumption also increases by a bit less than productivity, although it is closer to the 1-percent increase in productivity. One subtle difference between the TDP and SDP cases is that there are now movements in the fraction of firms adjusting $\left(\omega_{0, t}\right)$. Under SDP, on impact, there is an increase in the fraction of firms adjusting in response to higher deflation since firms' relative prices increase more quickly than before. There is a high correlation between the responses of inflation and the fraction of firms adjusting, which reflects the fact that firms' adjustment decision crucially depends on the expected path of the price level.

Despite the conclusion that the long-run response to a productivity shock under SDP is largely similar to that under TDP, I note that there are some important quantitative differences in the dynamics. The differences are quantitatively small since in this case the optimal policy is close to complete price stability, in which inflation only deviates slightly from its deterministic path - as shown in section 5 , however, they can be quantitatively large when the response of inflation is farther 
away from its deterministic steady-state point. In spite of these quantitatively-small differences, it is important to recognize that they still reflect the effect of the presence of endogenous timing and frequency of price adjustment under SDP. Recall that the task of the monetary authority is to optimally balance the costs of variations in various distortions. Since the variation in the additional adjustment cost (menu cost) distortion under SDP is minimized when inflation stays constant, one might think that the optimal response should involve a smaller inflation variation under SDP. Yet, as shown in Figure 5, inflation is actually more variable under SDP than under TDP. This conjecture misses the changing nature of the relative costs of various distortions and the policy tradeoff between various stabilization goals faced by the monetary authority under SDP.

The optimal policy response can be understood as follows. First, note that for a given change in inflation, the variation in the relative-price distortion is smaller under SDP than under TDP. This smaller price dispersion is due to the fact that firms are able to optimally respond to changing inflation. For example, if inflation deviates farther away from zero or a trend, additional firms will choose to adjust so that prices are more closely synchronized. Under TDP, firms do not have this opportunity and will only adjust if they are given the exogenous signal to adjust, so that there is higher price dispersion. This lower relative-price-distortion cost of inflation variation under SDP means that the monetary authority can "afford" to let inflation vary more and to optimally put more weight on the stabilization of other distortions or variables. For example, this is apparent in the response of the nominal rate, which affect the variations in the two monetary distortions, depicted in Figure 5. The nominal rate varies by less under SDP, indicating that the optimal policy is closer to the Friedman rule. The monetary authority can also afford to stabilize the average markup distortion by more, which is apparent by looking at the consumption response relative to productivity. Compared to under TDP, consumption tracks productivity much closer under SDP, indicating a smaller decrease in the output gap. ${ }^{31}$ Overall, however, this modification to the policy tradeoff in response to a productivity shock is relatively small. Hence, from the timeless perspective, the optimal response under TDP is a good approximation to the optimal response under SDP.

\subsection{Government purchase shock}

So far I have exclusively discussed the optimal response to a productivity shock. Figure 6 now displays the dynamics when the economy is hit by a positive two standard-deviation government

\footnotetext{
${ }^{31}$ Government purchase is assumed to be at its zero steady-state level throughout this higher-productivity period, so that consumption is always equal to output.
} 
purchase shock. $^{32}$ A temporary, but persistent, government purchase shock can be thought as a temporary drain on economy's resources from the perspective of the representative household. Households thus choose to reduce consumption (top left panel of Figure 6) and increase work effort in response to this negative wealth effect. Since the increase in government purchase, and hence, the decrease in consumption, are temporary, the real interest rate is temporarily higher. Inflation movements are generally small so that the price level is largely stabilized around its steady state. These dynamic patterns occur under both the TDP and SDP assumptions. As noted by SchmittGrohe and Uribe (2007), the monetary authority chooses an allocation that resembles the allocation in the flexible-price case, but with due consideration regarding the presence of predetermined prices and monetary frictions. ${ }^{33}$

The conclusion regarding the optimal long-run dynamics in the SDP model versus the TDP model in the productivity shock case carries over to the case of a government purchase shock. In particular, inflation tends to be more variable and the optimal policy is closer to the Friedman rule under SDP. The latter point is apparent by a more muted nominal interest rate response under SDP as depicted in the top right panel of Figure 6. Once again, the lower cost of inflation variation on the relative-price distortion under SDP is responsible for this result. As in the productivity shock case, the response under SDP still closely tracks the response under TDP.

\subsection{Additional discussions}

The role of monetary distortions Most commonly optimal monetary policy studies in the literature assume the presence of only two market distortions: the relative-price distortion and the markup distortion. One may then wonder about the importance of the monetary distortions for the above results.

From the model-solution standpoint, these additional distortions are needed so that the SDP model used here has a determinate steady-state solution with finite $J$. Note that in the absence of monetary distortions, the steady-state inflation under the optimal policy is zero-without some additional, potentially restrictive, assumptions, all firms would then optimally choose not to adjust forever in the steady state, i.e. $J \rightarrow \infty$. This would make the model intractable and infeasible to solve quantitatively.

\footnotetext{
${ }^{32} \mathrm{As}$ in the productivity shock case, the response is normalized so that government purchase increases by $1 \%$ on impact.

${ }^{33}$ Schmitt-Grohe and Uribe (2007) consider a permanent increase in the growth rate of government purchase. Yet, the same intuition holds in the case of a temporary shock.
} 
But more importantly, monetary distortions play an important role for the near steady-state dynamics results presented above since these distortions cause the monetary authority to face an additional policy tradeoff. The presence of this additional tradeoff in turn makes it possible for us to observe the change in the policy tradeoffs faced by the monetary authority when firms' pricing decisions are state-dependent. For example, as is familiar and shown previously, there is no tradeoff between inflation and output gap stabilizations if only the relative-price and markup distortions are present when the economy is hit by a temporary productivity shock - the monetary authority can optimally choose the allocation in which both distortions continue to be minimized. This result continues to be the case even under the SDP environment. To observe the change in the policy tradeoffs under the productivity shock, we thus need the monetary authority to be faced by a policy tradeoff in the first place, which is provided by the presence of the monetary distortions. When the economy is hit by a government purchase shock, on the other hand, the monetary authority does face a tradeoff between inflation and output gap stabilizations even when monetary distortions are absent. We should still then observe some differences between the impulse responses under SDP and those under TDP, provided we make additional assumptions so that steady state under the optimal policy is determinate. The differences between SDP and TDP responses are not therefore due to the additional presence of monetary distortions per se as claimed by Nakov and Thomas (2010). ${ }^{34}$ As long as there exists a policy tradeoff faced by the monetary authority we should still observe the results exhibited above.

The second-order approximate solution The solution methodology employed in this paper allows the model to be solved up to a second-order approximation and for the associated impulse

\footnotetext{
${ }^{34}$ Nakov and Thomas (2010), which came out in circulation after the first version of this paper, also study optimal monetary policy under SDP using the model of Dotsey, King, and Wolman (1999), but without monetary distortions. To obtain a determinate optimal steady-state solution with finite $J$ and non-zero mass of firms adjusting for $j<J$, they make additional assumptions and restrictions on the distribution of the fixed adjustment costs. They conclude that the responses under SDP and TDP are identical and claim that the results in this paper are entirely due to the additional presence of monetary distortions. This conclusion is mainly based on the impulse responses in their figure 2, which shows, among others, that the optimal response to a productivity shock is identical under TDP and SDPand inflation does not deviate from its zero steady-state inflation. Yet, as explained in the main text, one cannot possibly observe the change in the policy tradeoffs created by the presence of SDP in an environment in which there doesn't exist a policy tradeoff in the first place, as is the case in Nakov and Thomas under the productivity shock. In their figure 2, it is therefore expected that inflation response should be identical under SDP and TDP. In fact, as shown in their figure 3, the responses under SDP when the economy is hit by a cost-push shock-a case in which there is a tradeoff between inflation and output-gap stabilizations even when monetary distortions are absent-are indeed not the same as the responses under TDP. Even though the differences are quantitatively small there (due to fact that the optimal timeless-perspective policy is close to price stability), we can indeed still observe the change in the tradeoffs faced by the monetary authority.
} 
responses to be readily computed. Under the timeless perspective assumption where the optimal policy is close to price stability and when the economy was initially at the steady state prior to a shock, we should not expect much differences, both qualitatively and quantitatively, between the first-order and the second-order impulse responses. ${ }^{35}$ However, this may not be the case under several scenarios where these two assumptions do not hold. One example would be a case where the monetary authority is faced with a decision on how to optimally disinflate a high-inflation economy. Another example is a scenario in which the economy is repeatedly hit by a series of shocks, instead of a one-time shock. These two examples may be able to fully reveal the state-dependence nature of state-dependent models such as in this paper, especially in relation to the optimal monetary policy dynamics. For this, clearly we need to move away from the first-order or linear approximate solution. Thoroughly analyzing SDP models where a second- or higher-order approximate solution is employed is therefore an important future research agenda.

\section{Robustness}

In this section I perform several robustness analyses to check whether the results in section 3 above still hold under several parametrizations in the model, focusing on the responses to a productivity shock. Similar results are found under a government purchase shock.

The first robustness check involves a case where the demand elasticity is lower, i.e. $\varepsilon=7$. Other parameter values are set as in Table 1 - except for the largest possible fixed adjustment cost, $B$, where it is adjusted so that we still obtain $J=6$. This case thus corresponds to a case in Table 2 where the optimal steady-state inflation under SDP is $-1.5 \%$ per annum. Figure 7 .A shows that the main result in section 3 continues to hold. That is, it is still optimal for the monetary authority to let inflation vary more when firms' pricing decisions are state dependent.

Figure 7.B shows a case where $B$ is set so that $J=9$-all other parameter values are set as previously. ${ }^{36}$ As is expected, when $J$, the longest possibly period in which firms' prices can remain fixed, is higher, the impulse responses look smoother compared to the benchmark case of $J=6$. Yet, we can still clearly observe the same change in the policy tradeoffs under SDP in comparison to its TDP counterpart.

\footnotetext{
${ }^{35}$ This is indeed the case, as shown in an earlier version of this paper.

${ }^{36}$ The optimal steady-state inflation in this case is equal to $-0.565 \%$ per annum under SDP. It is equal to $-0.561 \%$ per annum under the TDP assumption.
} 
Finally, I look at the parametrization of the price adjustment cost distribution. Various choices for the values of the left parameter and the right parameter of the Beta distribution do not change the main conclusion in section $3{ }^{37}$ Changing the distribution to the one used in Dotsey and King (2005) also preserves the above results. ${ }^{38}$

\section{The start-up problem}

I consider in this section a departure from the timeless perspective policy. One should note that the optimal policy from the timeless perspective is not the true Ramsey solution, which generally involves treating the starting period of optimal policy implementation differently than the subsequent periods. That is, a Ramsey planner takes into account that there is no past commitment that she must abide by in the starting period during which the optimal state-contingent plan is set and announced. The timeless perspective optimal policy is thus suboptimal in a sense that it is welfare-dominated by the true Ramsey solution, although it welfare-dominates other timeconsistent rules. ${ }^{39}$ This so-called "start-up problem" means that the policy rule in the starting period is different than that in the subsequent periods. One reason to analyze this start-up problem is that it essentially measures the cost of adopting the timeless perspective policy instead of the true Ramsey policy, which I undertake in this section.

In the context of monetary models with monopolistic competition like the model in this paper, this start-up problem takes the form of a monetary authority that generates surprise inflation in the starting period of optimal policy implementation. It is optimal to do so since the economy operates inefficiently due to firms' monopoly power. Generating temporary higher inflation would erode the markup of firms when prices are sticky, and hence, would temporarily bring the economy closer to the first-best allocation.

One question of interest that one can ask is whether the start-up inflation would be more muted under the SDP assumption. An implication of SDP is that inflation is more variable since firms can change their prices more freely. This property of SDP means that the monetary authority has less

\footnotetext{
${ }^{37}$ Results are available upon request.

${ }^{38}$ Dotsey and King (2005) assume that the CDF of adjustment cost is $F(x ; a, b)=K_{1} \tan (a+(b-a) x)+K_{2}$. Here, $a$ and $b$ are parameter values $(b>a)$ and $K_{1}$ and $K_{2}$ are appropriately chosen constant parameters that are functions of $a$ and $b$.

${ }^{39}$ One can view the optimal policy from the timeless perspective as time consistent since if the policy itself is assumed to have been implemented since time immemorial, there is no reason for the monetary authority to deviate from this behavior now or in the future.
} 
leverage over real activity - or from a standpoint of the New Keynesian Phillips curve, the slope of the Phillips curve is steeper under SDP than under TDP. Hence, the conjecture that the start-up inflation would be lower under SDP is a reasonable one to make. As we see below, this conjecture is incorrect for the very reason that the policy tradeoff is altered under SDP.

We can analyze the dynamics of the start-up problem in the context of the present model by setting the lagged policy multipliers to zero since these multipliers essentially represent the monetary authority's past commitments. ${ }^{40}$ Furthermore, I assume that the economy was at the steady state prior to $t=0$ and there is zero stochastic disturbance or shock. These last two assumptions make sure that the dynamics coming from this exercise are entirely due to the startup problem and not to the transition across steady states or to the response to an exogenous shock. After the starting period, the monetary authority is assumed to follow the timeless-perspective policy rule. We can then look at the response of the economy based on these assumptions. For interested readers, appendix D provides further background on the analogous start-up problem in a simple linear-quadratic (LQ) framework under the time-dependent Calvo pricing as in Clarida, Galí, and Gertler (1999).

The start-up problem under TDP Let's first look at the start-up problem under TDP, with the dynamics depicted in Figure 8. As in the discussion above, the monetary authority optimally chooses to generate higher inflation in the starting period of the precommitment policy. Inflation goes up initially by more than 250 basis points from its steady state and this higher-than-steadystate inflation lasts for about five to six quarters. The transition speed of inflation back to its steady-state level mainly depends on the probabilities of price adjustment $\left(\alpha_{j}\right)$, which are assumed to be constant under TDP. ${ }^{41}$ The top right panel of Figure 8 displays the motivation behind this surprise inflation: the temporary increase in inflation temporarily erodes firms' average markup, which stimulates consumption and output. (Since there is no government purchase, output and consumption dynamics are identical.) Cumulatively over the entire stimulation periods, consumption is higher relative to its steady state by about 6 percent. Both the real and nominal interest rates decrease during these early periods, but the nominal rate decreases less on average due to expected inflation.

\footnotetext{
${ }^{40}$ Specifically, I assume that the optimal policy's starting period is at $t=0$ and set the vector of state variables $s_{0}^{2}$ to zero, which reflect the fact that there is no past commitment in this starting period.

${ }^{41}$ This also holds in the analysis of the start-up problem in a simple LQ framework in appendix D.
} 
Note that the size of the start-up inflation depends on several factors. First, it depends on the size of the firms' monopoly power and hence, the size of the average markup distortion, in the economy. The higher is the markup distortion, the higher the start-up inflation is. ${ }^{42}$ Second, it depends on the shorty-run inflation-output tradeoff, provided by the presence of predetermined prices. Other things held constant, the start-up inflation is lower if prices are more flexible as the ability of the monetary authority to stimulate real activity in the short run is more limited. Third, it depends on the relative cost of inflation variation since the optimal decision of the monetary authority to generate this surprise inflation and to erode the average markup is not a free lunch. In this case, higher inflation increases the size of the relative-price distortion (price dispersion), which affects the welfare of the representative agent. In determining the size of the start-up inflation, the monetary authority has to take into account these various factors. The last two factors are especially important when we consider the start-up problem under the corresponding SDP specification, which I discuss below.

The start-up problem under SDP Figure 9 compares the start-up problem in the SDP and TDP models. We can see that it is still optimal for the monetary authority to generate surprise inflation in the first period under the SDP assumption. Yet, there are two important differences regarding the dynamics. The first one involves the size of the start-up inflation at quarter zero. Under SDP, the surprise inflation is much higher: inflation jumps by more than a 500 basis point deviation from the steady state. This result can be understood as follows. As noted above, an economy under SDP can be thought as one with less nominal rigidity due to firms' ability to change their timing of price adjustment. An implication of this lower degree of nominal rigidity is that the monetary authority has less leverage over real activity. This is apparent if we look at the relative consumption (output) and average markup movements in the top right panel of Figure 9. Under SDP, the average markup is eroded by less and consumption increases by less than in the TDP case in spite of the higher increase in inflation. It is in this sense that the presence of endogenous timing of adjustment under SDP alters the short-run inflation-output tradeoff faced by the monetary authority. Yet, despite this lower leverage over real activity, it is optimal to generate a higher start-up inflation under SDP. This is precisely because the cost of inflation variation on the relative-price distortion is lower under SDP. That is, even though the decrease in the monetary

\footnotetext{
${ }^{42}$ If there were no markup distortion so that market-generated output level is efficient, there would be no need for the monetary authority to generate this surprise inflation.
} 
authority's leverage over real activity means that there is less incentive to generate surprise inflation, the changing nature of the policy tradeoff involving the relative-price distortion makes it optimal to increase inflation by more.

The second difference between the start-up dynamics under the TDP and SDP assumptions is in the transition of inflation back to its steady-state level. Under SDP, inflation is less persistent than under TDP. This is intuitive since more firms choose to adjust their prices in response to higher inflation in the SDP case, as can be seen in the bottom left panel of Figure 9.

To summarize, under the SDP environment, the lower cost of inflation variation in terms of relative price distortion gives rise to much higher start-up inflation under SDP. This conclusion is achieved even though the monetary authority has less leverage over real activity under SDP. As shown in appendix D, a similar result can also be observed in a simple LQ framework with Calvo pricing when we vary the parameter governing the probability of price adjustment. To a certain degree, the incorporation of SDP in this context can be thought as a Calvo model with a higher probability of price adjustment, provided that stabilization (welfare) weights are adjusted appropriately.

Welfare cost The start-up problem involves the monetary authority choosing to inflate (the true Ramsey policy) rather than adopting the timeless perspective policy. There is a cost associated with ignoring this start-up period. One way to quantify this cost is to compute the unconditional welfare cost associated with not taking this opportunity to generate surprise inflation in the starting period of policy implementation. Following Schmitt-Grohe and Uribe (2005, 2007), I define this welfare cost as the fraction of consumption that the representative household would be willing to give up in the benchmark policy environment without past commitment (the true Ramsey policy), so that it would be as well off to be in the alternative policy environment with past commitment (timeless perspective). This welfare cost, $w^{c}$, is implicit in the expression

$$
E_{0} \sum_{t=0}^{\infty} \beta^{t} u\left(\left(1-w^{c}\right) c_{t}^{c}, l_{t}^{c}\right)=E_{0} \sum_{t=0}^{\infty} \beta^{t} u\left(c_{t}, l_{t}\right),
$$

where the superscripts $c$ in consumption and leisure variables in the left-hand-side of the above expression indicate the contingent plans under the benchmark policy without past commitment. The expectation operator above makes clear that the starting implementation period of the optimal policy is at period $t=0$. Hence, we can compute the welfare cost $w^{c}$ using the second-order 
approximation method employed here. ${ }^{43}$

I find that under SDP, $w^{c}$ is equal to about 0.0088 percent. Using the 2008 nominal U.S. per capita personal consumption expenditures figure of $\$ 33,264$, this amounts to a welfare cost of about $\$ 2.92$ per capita per annum. This number means that the cost of adopting the timeless perspective policy is quite small, although it is not negligible. Hence, even though the timeless perspective policy is suboptimal, it is still a good enough representation of the true Ramsey solution.

\section{Conclusion}

This paper provides an analysis of optimal monetary policy under precommitment with the assumption that firms' pricing decisions are state dependent. The main finding from the analysis is that the presence of endogenous timing of price adjustment alters the tradeoff faced by the monetary authority. I also show that the cost of inflation variation on the relative-price distortion is lower under state-dependent pricing than under the standard time-dependent pricing assumption. An implication of this is that it is desirable for the monetary authority to put less weight on inflation stabilization, relative to other stabilization goals.

Several additional findings arise from the analysis in the paper. First, the optimal timeless perspective responses to both productivity and government purchase shocks under state-dependent pricing are shown to involve greater inflation variations. Yet the optimal response can still be characterized as an approximate price stability rule. Second, I show that even though the monetary authority has less leverage over real activity under state-dependent pricing, the optimal policy start-up problem involves a higher surprise inflation. Once again, the changing nature of the policy tradeoff is responsible for this result. I also show that the welfare cost associated with adopting the timeless perspective policy instead of the true Ramsey policy is quite small, which is an indication that the optimal policy from the timeless perspective is a good approximation to the true Ramsey solution.

In terms of future research, the analysis of the paper can be extended in several ways. The central focus of the present study is the characterization, and not the implementation, of optimal monetary policy under state-dependent pricing. However, to be useful for policymakers, one should consider the implementability issue in the future. Another important extension involves the driving

\footnotetext{
${ }^{43} \mathrm{~A}$ second- or higher-order approximation is generally needed for an accurate welfare computation. Kim and Kim (2003) show that using linear approximation to compute welfare can lead to spurious welfare reversals, which is due to the inaccuracy of the linear approximate solution.
} 
process in the model. In this paper, aggregate fluctuations are driven by two standard shocks in neoclassical models: productivity and government purchase shocks. It would be desirable to extend the analysis to a setup where there exists a cost-push shock as is common in the New Keynesian literature (e.g. Clarida, Galí, and Gertler, 1999). Since the presence of such a shock means that prices tend to move beyond the movement in excess demand, there will be a further nontrivial modification to the policy tradeoff in combination with the state-dependent pricing assumption. Yet another promising research avenue is in terms of the use of a second-order approximation method in characterizing the dynamics of the optimal response, given the state-dependence nature of the state-dependent pricing framework. 


\section{References}

Altig, David, Lawrence J. Christiano, Martin Eichenbaum, and Jesper Lindé. 2005. "Firm-Specific Capital, Nominal Rigidities, and the Business Cycle." Working Paper 11034. Cambridge, MA: National Bureau of Economic Research.

Bakhshi, Hasan, Hashmat Khan, and Barbara Rudolf. 2007. "The Phillips Curve Under StateDependent pricing." Journal of Monetary Economics 54(8): 2321-2345.

Basu, Susanto, and John G. Fernald. 1997. "Returns to Scale in U.S. Production: Estimates and Implications." Journal of Political Economy 105(2): 249-283.

Baumol, William J. 1952. "Transactions Demand for Cash." Quarterly Journal of Economics 67(4): $545-556$.

Benigno, Gianluca, and Pierpaolo Benigno. 2003. "Price Stability in Open Economies." Review of Economic Studies 70(4): 743-765.

Benigno, Pierpaolo, and Michael Woodford. 2004. "Optimal Stabilization Policy When Wages and Prices are Sticky: The Case of a Distorted Steady State." Working Paper 10839. Cambridge, MA: National Bureau of Economic Research.

Benigno, Pierpaolo, and Michael Woodford. 2005. "Inflation Stabilization and Welfare: The Case of a Distorted Steady State." Journal of the European Economic Association 3(6): 1185-1236.

Benigno, Pierpaolo, and Michael Woodford. 2008. "Linear-Quadratic Approximation of Optimal Policy Problems." Manuscript. Available at http://www.columbia.edu/ mw2230/LQgeneral080408.pdf.

Bils, Mark, and Peter J. Klenow. 2004. "Some Evidence on the Importance of Sticky Prices." Journal of Political Economy 112(5): 947-985.

Calvo, Guillermo A. 1983. "Staggered Prices in a Utility-Maximizing Framework." Journal of Monetary Economics 12(3): 383-398.

Chamley, Christophe. 1986. "Optimal Taxation of Capital Income in General Equilibrium with Infinite Lives." Econometrica 54(3): 607-622.

Christiano, Lawrence J., Martin Eichenbaum, and Charles Evans. 2005. "Nominal Rigidities and the Dynamic Effects of a Shock to Monetary Policy." Journal of Political Economy 113(1): 1-45.

Clarida, Richard, Jordi Galí, and Mark Gertler. 1999. "The Science of Monetary Policy: A New Keynesian Perspective." Journal of Economic Literature 37(4): 1661-1707.

Clarida, Richard, Jordi Galí, and Mark Gertler. 2000. "Monetary Policy Rules and Macroeconomic Stability: Evidence and Some Theory." Quarterly Journal of Economics 115(1): 148-180.

Cooley, Thomas F., and Gary D. Hansen. 1991. "The Welfare Costs of Moderate Inflations." Journal of Money, Credit, and Banking 23(3): 483-503.

Damjanovic, Tatiana, and Charles Nolan. 2006. "Relative Price Distortions and Inflation Persistence." Working Paper 0721. University of St. Andrews: Center for Dynamic Macroeconomic Analysis. 
Dotsey, Michael, and Peter N. Ireland. 1996. "The Welfare Cost of Inflation in General Equilibrium." Journal of Monetary Economics 37(1): 29-47.

Dotsey, Michael, and Robert G. King. 2005. "Implications of State-dependent Pricing for Dynamic Macroeconomic Models." Journal of Monetary Economics 53(1): 213-242.

Dotsey, Michael, Robert G. King, and Alexander L. Wolman. 1999. "State-Dependent Pricing and the General Equilibrium Dynamics of Money and Output." Quarterly Journal of Economics 114(2): 655-690.

Erceg, Christopher J., Dale W. Henderson, and Andrew T. Levin. 2000. "Optimal Monetary Policy with Staggered Wage and Price Contracts." Journal of Monetary Economics 46(2): 281-313.

Faia, Ester, and Tommaso Monacelli. 2004. "Ramsey Monetary Policy and International Relative Prices." Working Paper 344. European Central Bank.

Gertler, Mark, and John V. Leahy. 2008. "A Phillips Curve with an Ss Foundation." Journal of Political Economy 116(3): 533-572.

Golosov, Mikhail, and Robert E. Lucas Jr. 2007. "Menu Costs and Phillips Curves." Journal of Political Economy 115: 171-199.

Goodfriend, Marvin, and Robert G. King. 1997. "The New Neoclassical Synthesis and the Role of Monetary Policy." In NBER Macroeconomic Annual, ed. Ben S. Bernanke and Julio J. Rotemberg, 231-296. Cambridge, MA: The MIT Press.

Hernández, Kólver. 2004. "Inflation and Output Dynamics with State-Dependent Frequency of Price Changes." Manuscript. Boston College.

Johnston, Michael K., Robert G. King, and Denny Lie. 2008. "Recursive Optimal Policy Design: Nonlinear Decision Rules and Welfare." Manuscript. Boston University.

Johnston, Michael K., Robert G. King, and Denny Lie. 2009. "Straightforward Approximate Stochastic Equilibria for Nonlinear Rational Expectations Models." Manuscript. Boston University.

Khan, Aubhik, Robert G. King, and Alexander L. Wolman. 2003. "Optimal Monetary Policy." Review of Economic Studies 70(4): 825-860.

Kim, Jinill, and Sunghyun Henry Kim. 2003. "Spurious Welfare Reversals in International Business Cycle Models." Journal of International Economics 70(2): 471-500.

Kim, Jinill, Sunghyun Henry Kim, Ernst Schaumburg, and Christopher A. Sims. 2008. "Calculating and Using Second Order Accurate Solutions of Discrete Time Dynamic Equilibrium Models." Journal of Economic Dynamics and Control 32(11): 3397-3414.

King, Robert G., Charles I. Plosser, and Sergio Rebelo. 1988. "Production, Growth, and Business Cycles I: The Basic Neoclassical Model." Journal of Monetary Economics 21(2-3): 195-232.

King, Robert G., and Sergio Rebelo. 1999. "Resuscitating Real Business Cycles." In Handbook of Macroeconomics, ed. John B. Taylor and Michael Woodford, 927-1007. New York: Elsevier. 
King, Robert G., and Alexander L. Wolman. 1999. "What Should the Monetary Authority Do When Prices are Sticky?" In Monetary Policy Rules, ed. John B. Taylor, 349-398. Chicago: University of Chicago Press.

Kydland, Finn E., and Edward C. Prescott. 1980. "Dynamic Optimal Taxation, Rational Expectations, and Optimal Control" Journal of Economic Dynamics and Control 2(1): 79-91.

Levin, Andrew T. 1991. "The Macroeconomic Significance of Nominal Wage Contract Duration." Discussion Paper 91-08. University of California, San Diego.

Levin, Andrew T., Alexei Onatski, John C. Williams, and Noah Williams. 2006. "Monetary Policy Under Uncertainty in Micro-Founded Macroeconometric Models." In NBER Macroeconomic Annual, ed. Daron Acemoglu, Kenneth S. Rogoff, and Ben S. Bernanke, 229-312. Cambridge, MA: The MIT Press.

Lombardo, Giovanni, and Alan Sutherland. 2007. "Computing Second-Order-Accurate Solutions for Rational Expectation Models Using Linear Solution Methods." Journal of Economic Dynamics and Control 31(2): 515-530.

Lucas, Robert E., Jr. 1980. "Equilibrium in a Pure Currency Economy." In Models of Monetary Economies, ed. John H. Kareken and Neil Wallace, 131-145. Federal Reserve Bank of Minneapolis.

Magnus, Jan R., and Heinz Neudecker. 2002. Matrix Differential Calculus with Applications in Statistics and Econometrics. West Sussex, England: John Wiley \& Sons.

Marcet, Albert, and Ramon Marimon. 1999. "Recursive Contracts." Manuscript.

Nakamura, Emi, and Jón Steinsson. 2008. "Five Facts about Prices: A Reevaluation of Menu Cost Models." Quarterly Journal of Economics 123(4): 1415-1464.

Nakov, Anton, and Carlos Thomas. 2010. "Optimal Monetary Policy with State-Dependent Pricing." European Central Bank Working Paper 1250.

Prescott, Edward C. 1987. "A Multiple Mean-of-Payment Model." In New Approaches to Monetary Economics, ed. W.A. Barnett and K.J. Singleton, 42-51. Cambridge, England: Cambridge University Press.

Ravn, Morten O. 2005. "Labor Market Dynamics and the Business Cycles: Structural Evidence for the United States." Scandinavian Journal of Economic 109(4): 743-777.

Rotemberg, Julio J., and Michael Woodford. 1999. "Interest Rate Rules in an Estimated Sticky Price Model." In Monetary Policy Rules, ed. John B. Taylor, 57-119. Chicago: University of Chicago Press.

Schmitt-Grohe, Stephanie, and Martin Uribe. 2004. "Solving Dynamic General Equilibrium Models Using a Second-Order Approximation to the Policy Function." Journal of Economic Dynamics and Control 28(1): 755-775.

Schmitt-Grohe, Stephanie, and Martin Uribe. 2005. "Optimal Fiscal and Monetary Policy in a Medium-Scale Macroeconomic Model." In NBER Macroeconomic Annual, ed. Mark Gertler and Kenneth S. Rogoff, 383-425. Cambridge, MA: The MIT Press. 
Schmitt-Grohe, Stephanie, and Martin Uribe. 2007. "Optimal Inflation Stabilization in a MediumScale Macroeconomic Model." In Monetary Policy under Inflation Targeting, ed. Klause SchmidtHebbel and Frederic Mishkin, 124-186. Central Bank of Chile.

Stockman, Alan C. 1981. "Anticipated Inflation and the Capital Stock in a Cash-in-Advance Economy." Journal of Monetary Economics 8(3): 387-393.

Taylor, John B. 1980. "Aggregate Dynamics and Staggered Contracts." Journal of Political Economy 88(1): 1-23.

Tobin, James. 1956. "The Interest Elasticity of the Transactions Demand for Cash." Review of Economics and Statistics 38(3): 241-247.

Woodford, Michael. 2002. "Inflation Stabilization and Welfare." Contributions to Macroeconomics 2(1). Berkeley Electronic Press.

Woodford, Michael. 2003. Interest and Prices: Foundations of a Theory of Monetary Policy. Princeton, NJ: Princeton University Press.

Yun, Tack. 1996. "Nominal Price Rigidity, Money Supply Endogeneity, and Business Cycles." Journal of Monetary Economics 37(4): 345-370.

Yun, Tack. 2008. "Optimal Monetary Policy and Relative Price Distortions." American Economic Review 95(1): 89-109. 


\section{Tables and Figures}

Table 1: Calibrated Parameters

\begin{tabular}{|c|c|}
\hline Rate of time preference $(\beta)$ & 0.99 \\
\hline Labor supply elasticity $(\phi)$ & 1 \\
\hline Elasticity of intertemporal substitution $(\sigma)$ & 1 \\
\hline Scale parameter in the utility $(\chi)$ & 3.59 \\
\hline Demand elasticity $(\varepsilon)$ & 10 \\
\hline \multicolumn{2}{|l|}{ Fixed adjustment cost distribution (Beta) } \\
\hline Beta left parameter $\left(a_{l}\right)$ & 2.10 \\
\hline Beta right parameter $\left(a_{r}\right)$ & 1 \\
\hline The largest fixed cost $(B)$ & 0.00057 \\
\hline \multicolumn{2}{|l|}{ Credit cost distribution (generalized Beta) } \\
\hline Mass of goods with zero credit cost $(\check{\xi})$ & 0.639 \\
\hline Beta left parameter $\left(a_{1}\right)$ & 2.806 \\
\hline Beta right parameter $\left(a_{2}\right)$ & 10.446 \\
\hline The largest credit cost $\left(\Omega_{c}\right)$ & 0.013 \\
\hline \multicolumn{2}{|l|}{ Productivity shock } \\
\hline Persistence parameter $\left(\rho_{a}\right)$ & 0.95 \\
\hline Standard deviation of shock $\left(\sigma_{a}\right)$ & 0.0072 \\
\hline \multicolumn{2}{|l|}{ Government purchase shock } \\
\hline Persistence parameter $\left(\rho_{g}\right)$ & 0.90 \\
\hline Standard deviation of shock $\left(\sigma_{g}\right)$ & 0.008 \\
\hline
\end{tabular}


Table 2: Steady-state annualized inflation under optimal policy

\begin{tabular}{|l|c|c|}
\hline & SDP & TDP \\
\hline Benchmark ("full" distortions) & $-0.993 \%$ & $-0.988 \%$ \\
Lower $\varepsilon(\varepsilon=7)$ & $-1.502 \%$ & $-1.489 \%$ \\
Eliminating variations in & & \\
\hline Shopping-time & & \\
Monetary wedge & $-0.471 \%$ & $-0.466 \%$ \\
Shopping-time and monetary wedge & $-0.661 \%$ & $-0.657 \%$ \\
Markup & $-1.048 \%$ & $-1.048 \%$ \\
\hline
\end{tabular}

Notes: (1) the TDP model is constructed under the assumptions that the probabilities of price adjustments $\left(\left\{\alpha_{j}\right\}_{j=1}^{J-1}\right)$ and firms' distribution $\left(\left\{\omega_{j}\right\}_{j=0}^{J-1}\right)$ are equal to the steady-state values under TDP, with the same $J=6 ;(2)$ the shopping-time distortion is eliminated by setting $\int_{0}^{\left(R_{t} c_{t} / w_{t}\right)} x d F(x)$ in equation (12) to a constant and resolving the optimal policy problem; (3) the monetary wedge distortion is eliminated by setting $R_{t}\left(1-\xi_{t}\right)$ in equation (10) to a constant and resolving the optimal policy problem; (4) the markup distortion is eliminated by setting $w_{t} / a_{t}$ to a constant and resolving the optimal policy problem. 
Figure 1: Steady state implications of various distortions
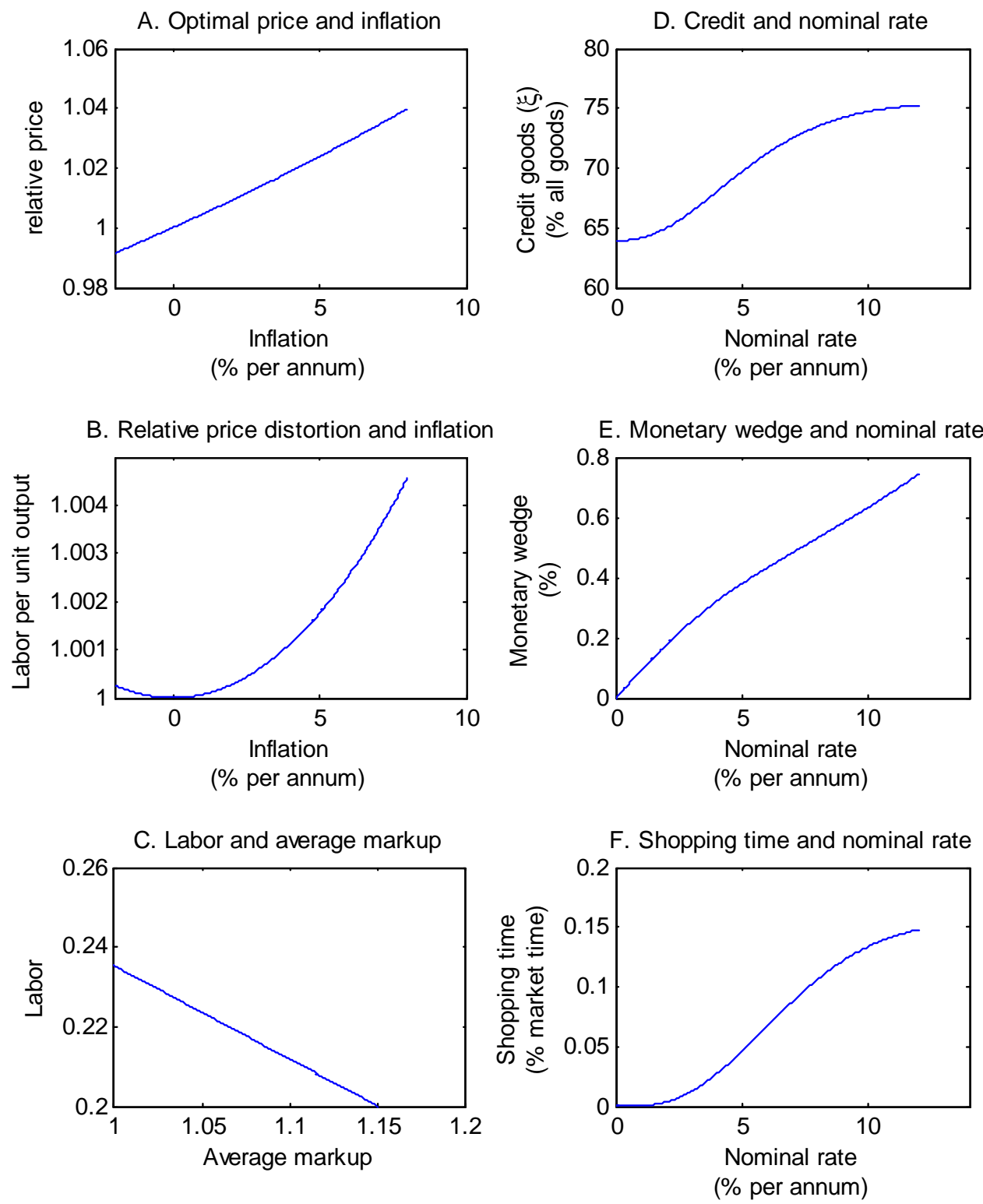

Notes: (1) panels A, B, and C are generated using $J=6$ with $\left\{\omega_{j}\right\}_{j=0}^{J-1}$ and $\left\{\alpha_{j}\right\}_{j=1}^{J-1}$ equal to their steady-state values under the optimal policy presented in Figure 2, with monetary and menu cost distortions are assumed to be absent; (2) panels $\mathrm{D}, \mathrm{E}$, and $\mathrm{F}$ are constructed using a Beta distribution for the credit cost distribution, with parameter values as in table 1 - further, I assume constant $n^{y}=0.2$ and $w=a=1$ so that $c=a \cdot n y=0.2$, as the nominal interest rate $(R)$ varies. 
Figure 2: Steady-state probability $\left(\alpha_{j}\right)$ and distribution $\left(\omega_{j}\right)$ of price adjustment Optimal policy under SDP
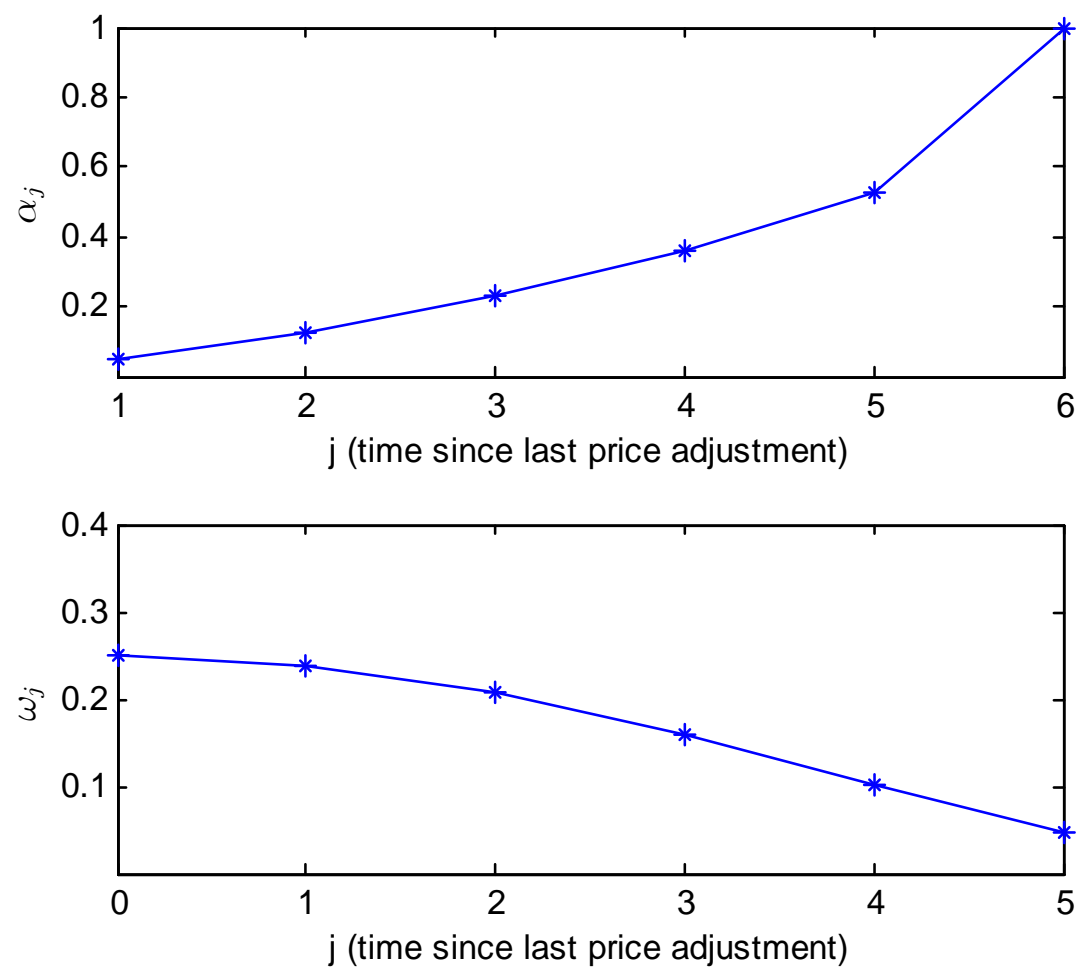

Notes: (1) the longest period of price fixity is $J=6$; (2) all market distortions are present (full distortions); (3) the horizontal $(j)$ axis is in quarters. 
Figure 3: Optimal timeless perspective responses to a productivity shock RBC vs. TDP cashless

First-order approximation
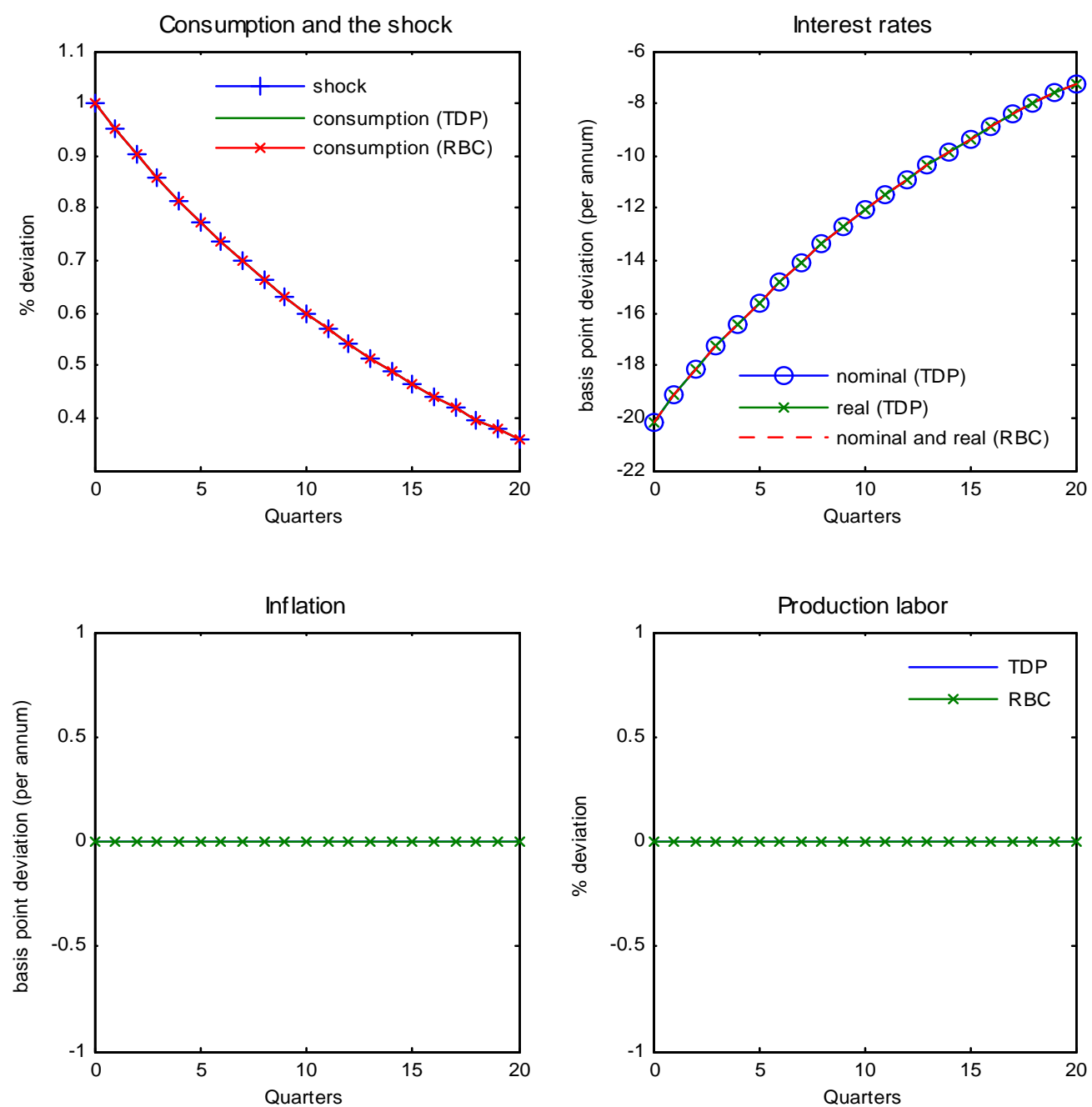

Notes: (1) $R B C$ refers to the dynamics of a real business cycle model with flexible price and where firms are monopolistically competitive; (2) TDP cashless refers to the dynamics under TDP model when monetary distortions (shopping-time and monetary wedge) are absent; (3) the shock size is 2 standard deviation, normalized so that productivity increases by 1 percent on impact; (4) the TDP model is constructed under the assumptions that the probabilities of price adjustments $\left(\left\{\alpha_{j}\right\}_{j=1}^{J-1}\right)$ and firms' distribution $\left(\left\{\omega_{j}\right\}_{j=0}^{J-1}\right.$ are equal to the steady-state values under TDP, with the same $J=6$. 
Figure 4: Optimal timeless perspective responses to a productivity shock TDP cashless vs. TDP money

First-order approximation
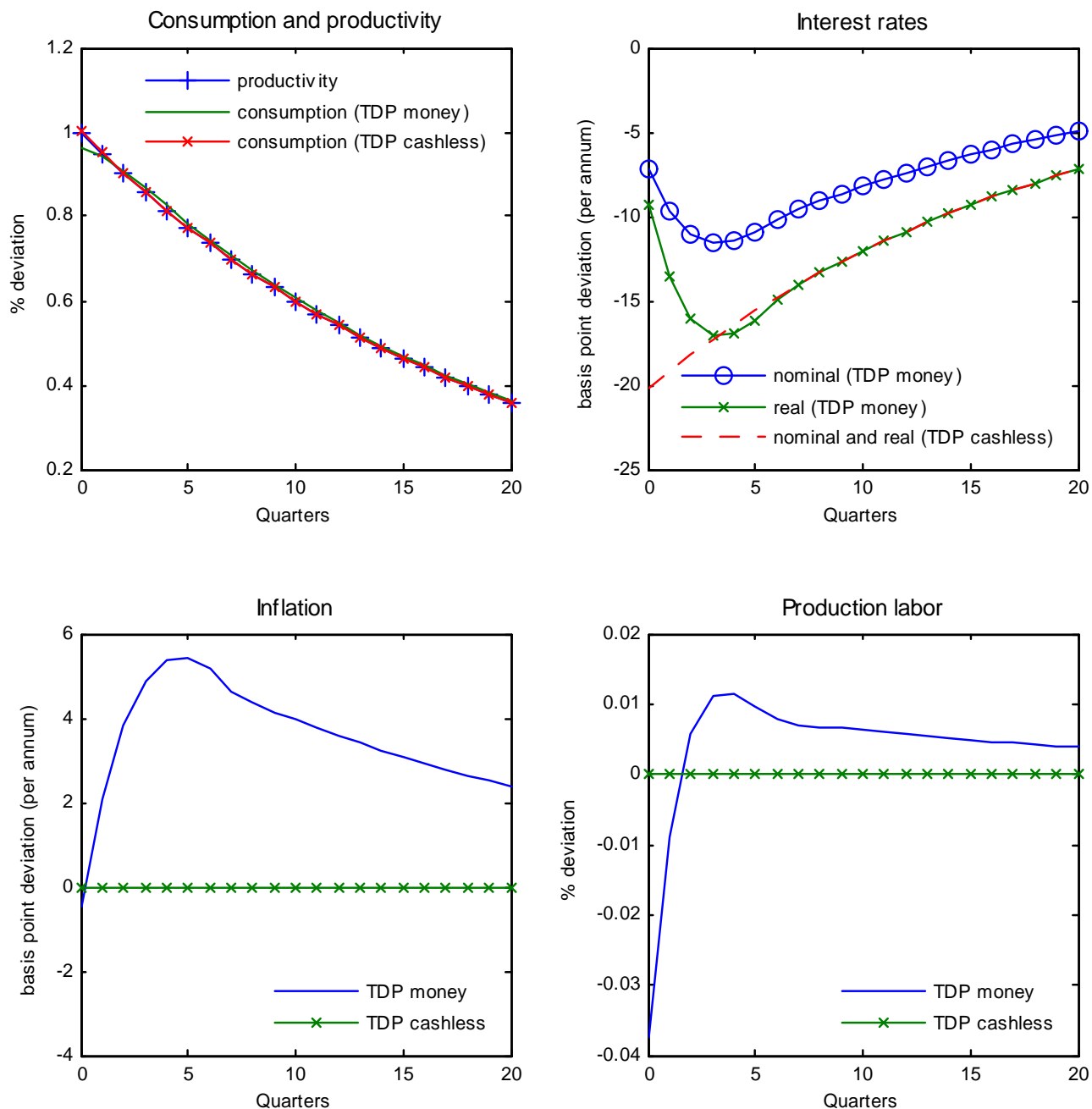

Notes: (1) TDP cashless refers to dynamics under TDP model when monetary distortions (shopping-time and monetary wedge) are absent; (2) TDP money refers to the dynamics under TDP model when all distortions, including monetary distortions, are present; (3) the shock size is 2 standard deviation, normalized so that productivity increases by 1 percent on impact; (4) the TDP model is constructed under the assumptions that the probabilities of price adjustments $\left(\left\{\alpha_{j}\right\}_{j=1}^{J-1}\right)$ and firms' distribution $\left(\left\{\omega_{j}\right\}_{j=0}^{J-1}\right.$ are equal to the steady-state values under TDP, with the same $J=6$. 
Figure 5: Optimal timeless perspective responses to a productivity shock TDP vs SDP

First-order approximation
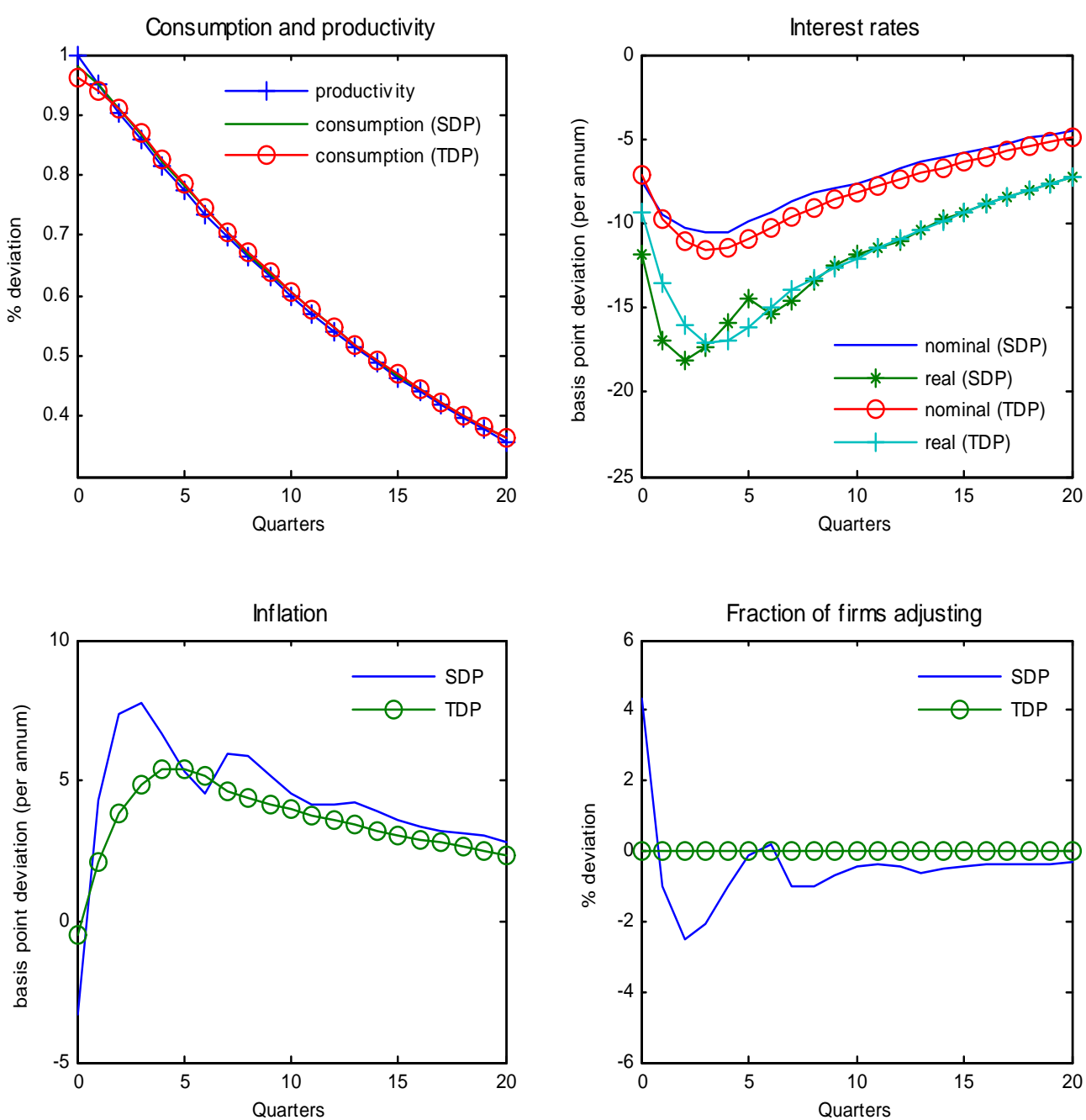

Notes: (1) the figure is constructed under the assumption that all distortions are present; (2) the shock size is 2 standard deviation, normalized so that productivity increases by 1 percent on impact; (3) the TDP model is constructed under the assumptions that the probabilities of price adjustments $\left(\left\{\alpha_{j}\right\}_{j=1}^{J-1}\right)$ and firms' distribution $\left(\left\{\omega_{j}\right\}_{j=0}^{J-1}\right.$ are equal to the steady-state values under TDP, with the same $J=6$. 
Figure 6: Optimal timeless perspective responses to a government purchase shock TDP vs SDP

First-order approximation
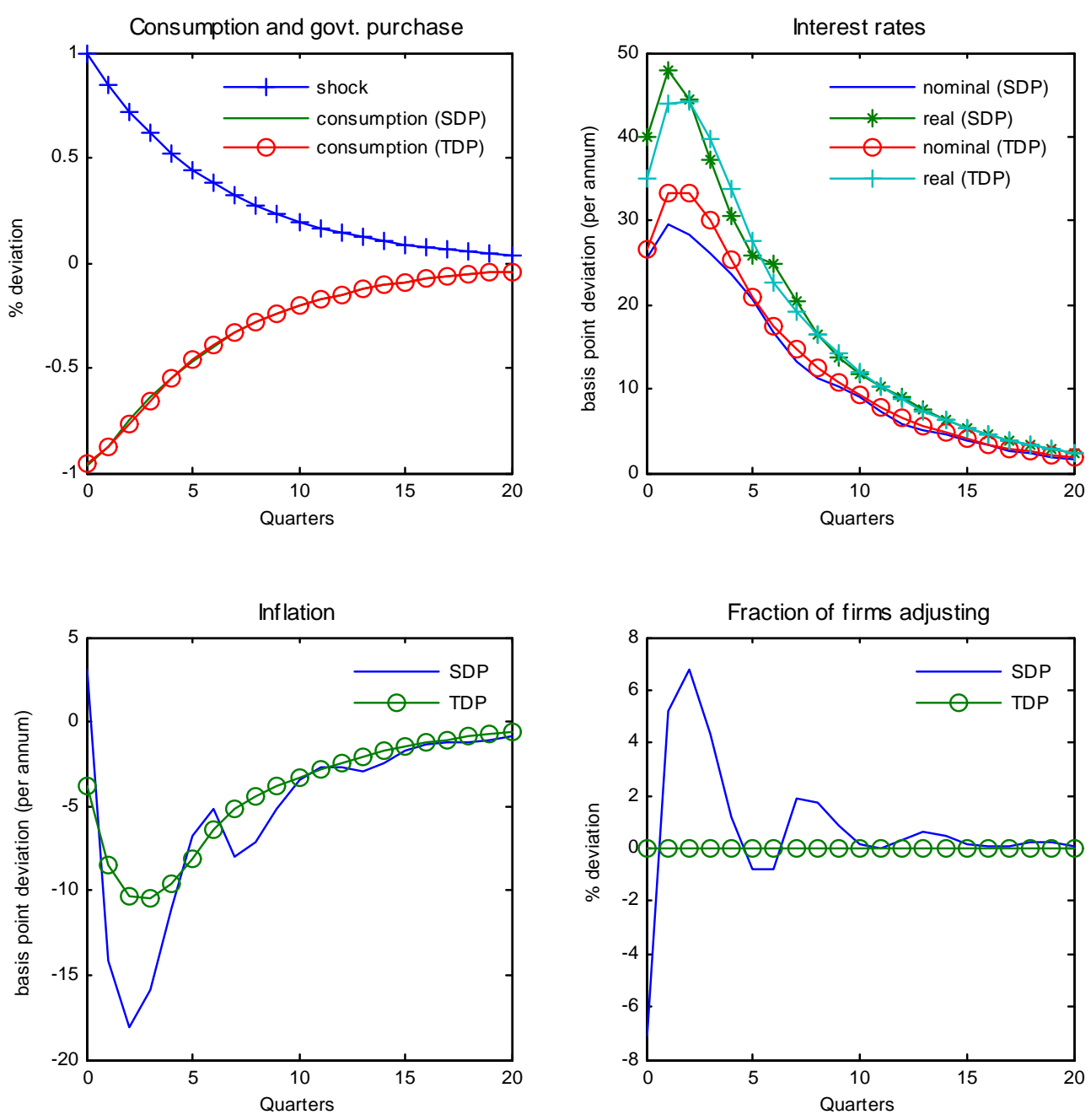

Notes: (1) the figure is constructed under the assumption that all distortions are present; (2) the shock size is 2 standard deviation, normalized so that productivity increases by 1 percent on impact; (3) the TDP model is constructed under the assumptions that the probabilities of price adjustments $\left(\left\{\alpha_{j}\right\}_{j=1}^{J-1}\right)$ and firms' distribution $\left(\left\{\omega_{j}\right\}_{j=0}^{J-1}\right.$ are equal to the steady-state values under TDP, with the same $J=6$. 
Figure 7.A: Optimal timeless perspective responses to a productivity shock TDP vs SDP; First-order approximation; $\varepsilon=7, J=6$
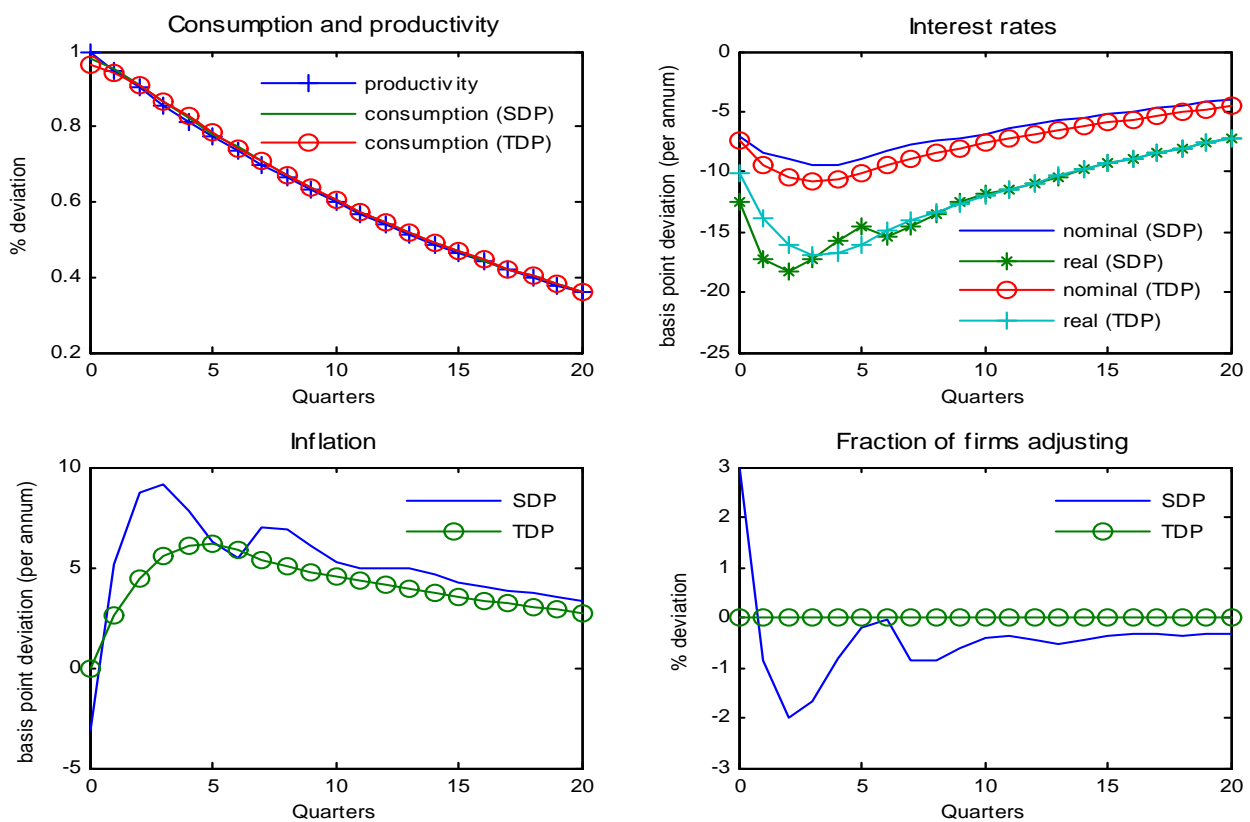

Figure 7.B: Optimal timeless perspective responses to a productivity shock TDP vs SDP; First-order approximation; $\varepsilon=10, J=9$
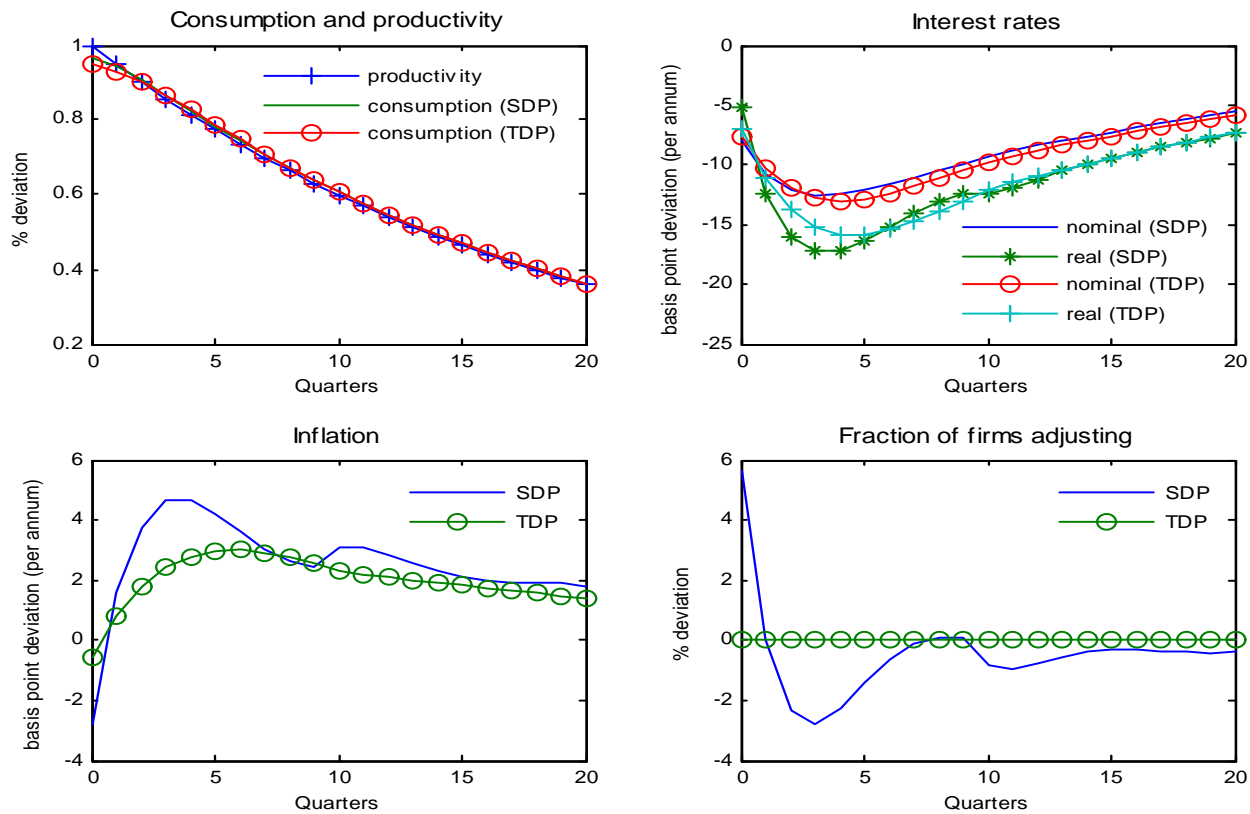
Figure 8: The start-up problem

Optimal policy under TDP
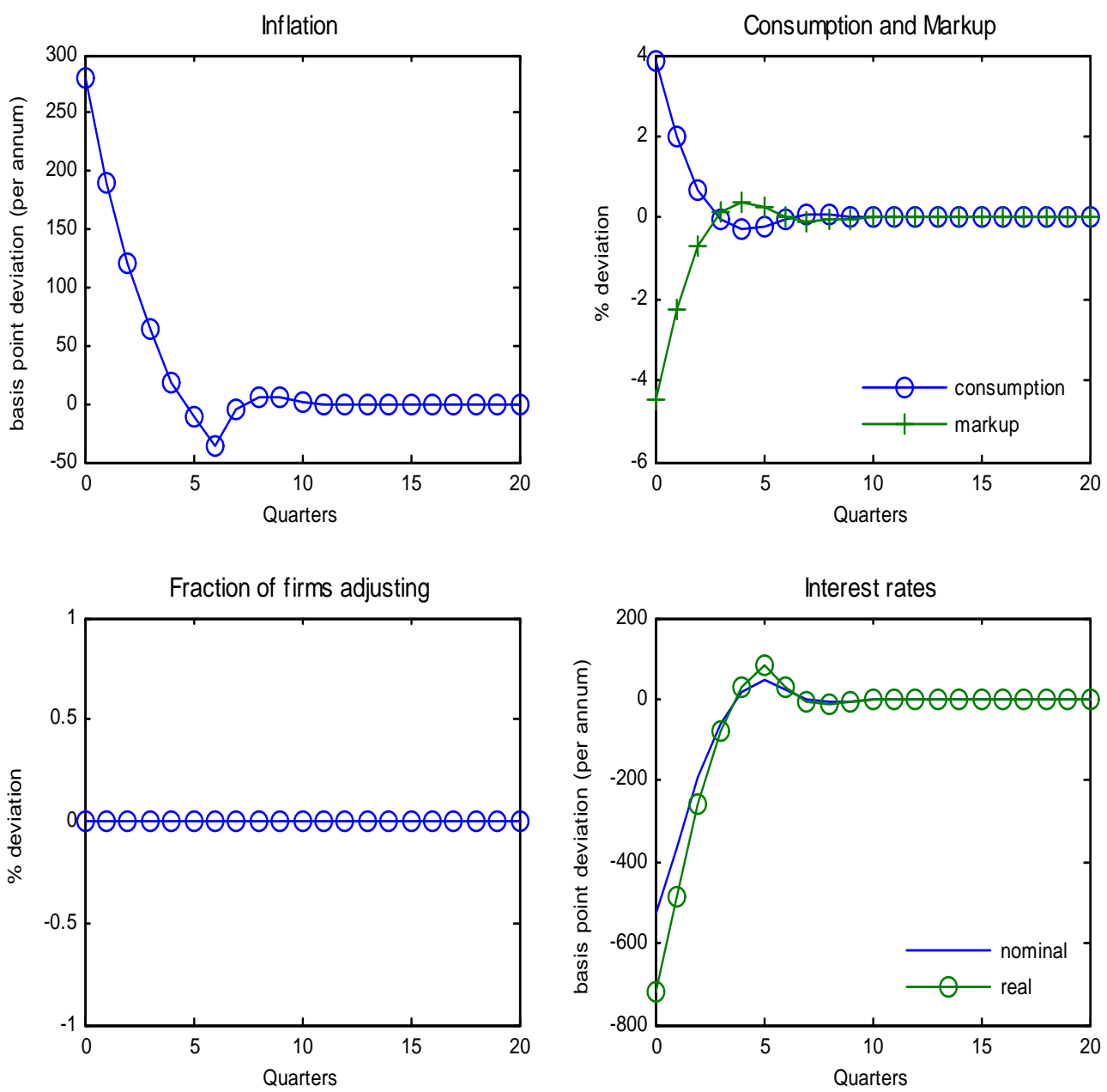

Notes: (1) the figure is constructed under the assumption of zero exogenous shock; (2) the starting point prior to the optimal policy implementation is the deterministic steady state under optimal policy; (3) all market distortions are assumed to be present. 
Figure 9: The start-up problem

Optimal policy under SDP vs. TDP
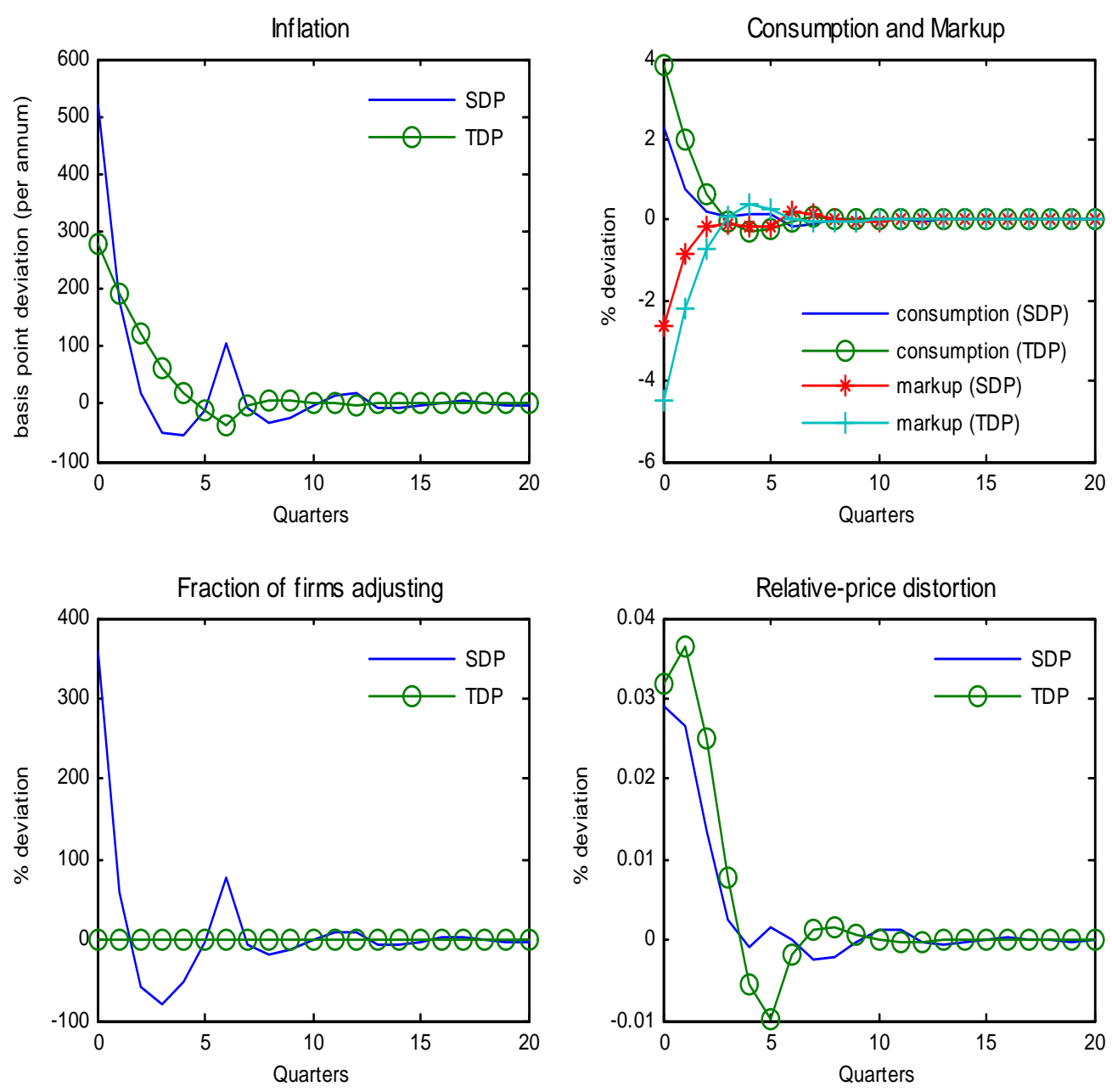

Notes: (1) the figure is constructed under the assumption of zero exogenous shock; (2) the starting point prior to the optimal policy implementation is the deterministic steady state under optimal policy; (3) all market distortions are assumed to be present. 


\section{Appendix}

\section{Appendix A: Details of households' intertemporal optimization problem}

Households choose the amount of final goods consumption $\left(c_{t}\right)$ and leisure $\left(l_{t}\right)$ to maximize the lifetime utility function,

$$
U=\sum_{t=0}^{\infty} \beta^{t}\left[\frac{1}{1-\sigma} c_{t}^{1-\sigma}+\chi \frac{1}{1-\phi} l_{t}^{1-\phi}\right]
$$

subject a budget constraint which I describe next. In each period households receive income from their total labor labor effort $\left(n_{t}\right)$ with nominal wage $W_{t}$, nominal one-period bond $\left(B_{t}\right)$ from the last period, and dividends from their ownership of the intermediate-goods firms $\left(Z_{t}\right)$. Households also inherit their previous period's portfolio of intermediate-goods firms $\left(x_{t}\right)$. The (pre-dividend) value of the portfolio of firms is $V_{t}$. They then pick the amount of consumption for that period, buy current period bonds $\left(B_{t+1}\right)$, and may buy more claims on the ownership of the intermediate goods firms. As mentioned in the main text, households optimally choose to finance some portions of consumption goods using money and the other portions using credit. Money is used since credit is costly, as in the transaction cost models of Baumol (1954) and Tobin (1956). Some goods are bought using credit because there is an opportunity cost of holding money (the nominal interest rate). Households thus accumulate debt from the credit use. This debt is assumed to be paid in the next period without any interest. Let $\xi_{t}$ be the proportion of credit goods at time $t$. If we let $\bar{P}_{t}$ as the nominal price of final consumption goods at time $t$, then the amount of nominal money holding is $M_{t}=\left(1-\xi_{t}\right) \bar{P}_{t} c_{t}$. The amount of nominal debt that must be paid in the next period is then $D_{t+1}=\xi_{t} \bar{P}_{t} c_{t}$. There is also a lump-sum tax $T_{t}$ that must be paid to the government. Hence, the budget constraint at time $t$ is given by

$$
M_{t}+\frac{1}{1+R_{t}} B_{t+1}+x_{t+1}\left(V_{t}-Z_{t}\right) \leq x_{t} V_{t}+B_{t}+W_{t} n_{t}-D_{t}+T_{t} .
$$

Note that one can make the nominal budget constraint into a real one by dividing it by the aggregate price level $P_{t}$ - in the case of the CES aggregator,

$$
P_{t}=\left[\int_{0}^{1} P_{t}(i)^{1-\varepsilon}\right]^{\frac{1}{1-\varepsilon}},
$$

where $P_{t}(i)$ is the nominal price of intermediate good $i$. On the price of final consumption goods, $\bar{P}_{t}$, the assumption is that the final-goods producers (retailers or households) must borrow to finance the production with interest rate $R_{t}$. Since the final-goods producers are perfectly competitive and receive zero profits, it follows that $\bar{P}_{t}=\left(1+R_{t}\right) P_{t}$.

As in Khan, King, and Wolman (2003), I assume that the each of the (mass) of final consumption goods has a random fixed time cost in terms of labor unit. (Although it is common to assume the representative household is assumed to purchase a single final consumption good, one can think of the final good as a continuum of final goods in a unit interval). Let $F($.) be the cumulative distribution function of the time cost. The largest time cost that households are willing to pay is then $F^{-1}\left(\xi_{t}\right)$. A good would be purchased with credit if its time cost is below this largest time cost, while money would be used to purchase a good if its time cost is above this value. The total transaction time at time $t$ in labor unit is then given by

$$
h_{t}=\int_{0}^{F^{-1}\left(\xi_{t}\right)} v d F(v) \text {. }
$$


Since labor must also be used in production $\left(n_{t}^{y}\right)$ and in price adjustment activity $\left(n_{t}^{p}\right)$, the total labor time is then

$$
n_{t}=n_{t}^{y}+n_{t}^{p}+h_{t}=1-l_{t} .
$$

We can then form a Lagrangian to solve for the optimization problem described above. Let $\lambda_{t}$ be the multiplier attached to the budget constraint. Solving for the Lagrangian and rearranging the first order necessary conditions lead to equations (8), (9), (10), (11), and (12) in the main text.

\section{Appendix B: Credit cost distribution and money demand function}

This appendix describes the credit cost distribution and the implied money demand function used in the main text. In this shopping-time assumption, the implied optimal choice between using money or credit based on households' efficiency conditions is given by

$$
F^{-1}(\xi)=\frac{R c}{w}
$$

where $F(\cdot)$ is the CDF of the credit cost distribution and $\xi$ is the proportion of goods bought using credit. If we let $P$ as the nominal price of final goods (so that $P c$ is the nominal consumption expenditure), it follows that the nominal demand for money is $M=(1-\xi) P c$. Combining this with the efficient credit used above, we have

$$
\frac{M}{P c}=1-F\left(\frac{R c}{w}\right)
$$

Note that when all goods are bought using money $\left(\xi=F\left(\frac{R c}{w}\right)=0\right)$, the money demand function then collapses to $\frac{M}{P}=c$, as in cash-in-advance models.

Khan, King, and Wolman (2003) uses the above expression to estimate the money demand function given a particular distribution $F(\cdot)$. Specifically, they assume that the distribution is a generalized Beta distribution of the form

$$
F(x)=\check{\xi}+\hat{\xi} \cdot F^{b e t a}\left(\frac{x}{\Omega} ; a_{1}, a_{2}\right)
$$

where $a_{1}$ and $a_{2}$ are the two parameters the Beta distribution and where the support has to be normalized by $\Omega$, the largest credit cost. Here, $\check{\xi}$ is the proportion of goods that have zero credit cost with the property $0<\check{\xi}<1$, so that there are always some goods with zero credit cost. $\hat{\xi} \leq 1-\check{\xi}$ is then the proportion of goods that have non-zero cost distributed according to Beta distribution. Given this specified distribution, Khan, King, and Wolman (2003) estimate the five parameters $\left(\check{\xi}, \hat{\xi}, a_{1}, a_{2}, \Omega\right)$ by minimizing the distance (sum of squared errors) between $1-\frac{M}{P c}$ and $F\left(\frac{R c}{w}\right)$ based on the money demand function above and given data for $M$ (nominal money), $P c$ (nominal consumption expenditure), $R$ (nominal interest rate), and $w$ (real labor compensation). The estimation used in this paper is for the sample period 1959:Q1 through 1989:Q4. The implied money demand elasticity based on the estimation is less than 0.3 in absolute value throughout the sample period used.

\section{Appendix C: Adjustment cost distribution}

The paper uses Beta distribution for the distribution of the price adjustment costs. Specifically, the PDF of the Beta distribution is

$$
g^{b e t a}\left(x ; a_{l}, a_{r}\right)=\frac{1}{\beta\left(a_{l}, a_{r}\right)}\left[x^{a_{l}-1}(1-x)^{a_{r}-1}\right],
$$



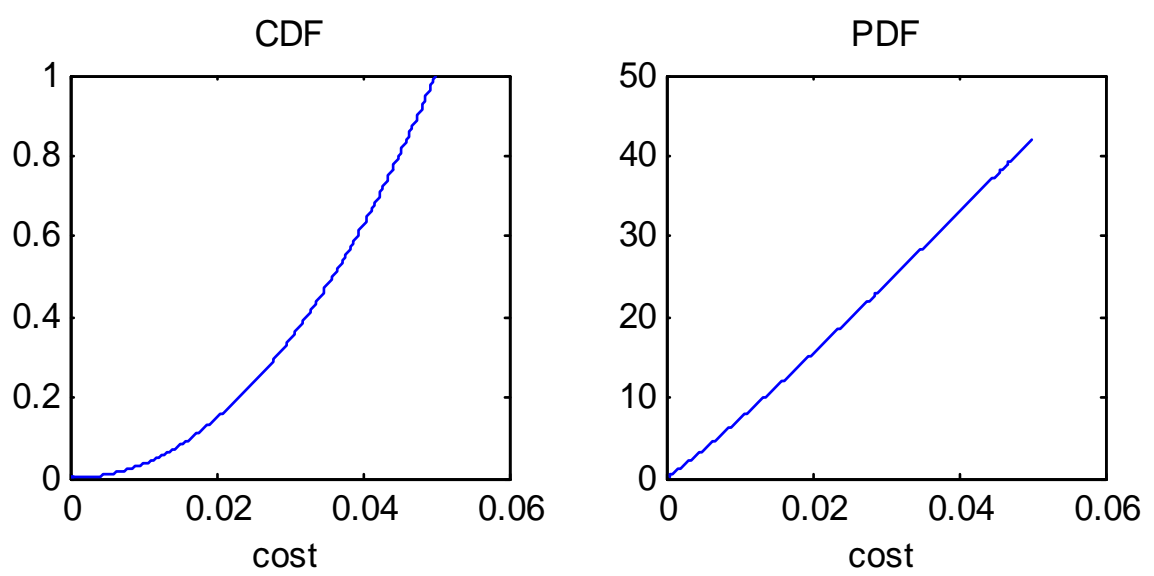

where $\beta\left(a_{l}, a_{r}\right)=\frac{\Gamma\left(a_{l}+a_{r}\right)}{\Gamma\left(a_{l}\right) \Gamma\left(a_{r}\right)}$ is the Beta function which is a normalization of the gamma function $\Gamma(\cdot)$. This Beta function can also be written as $\beta\left(a_{l}, a_{r}\right)=\int_{0}^{1} u^{a_{l}-1}(1-u)^{a_{r}-1} d u$. Note that the Beta distribution is known to be a flexible distribution in which various shapes of the PDF (increasing, decreasing, convex, concave, etc) can be attained for suitable choices of parameters $a_{l}$ and $a_{r}$. The CDF is given by

$$
G^{b e t a}\left(x ; a_{l}, a_{r}\right)=\frac{\beta_{x}\left(a_{l}, a_{r}\right)}{\beta\left(a_{l}, a_{r}\right)},
$$

where $\beta_{x}\left(a_{l}, a_{r}\right)$ is the incomplete beta function.

Since the support of the Beta distribution lies on a unit interval, $x \in[0,1]$, we need to normalize the support by the largest price adjustment $\operatorname{cost} B$, so that the PDF of the distribution of adjustment cost is given by

$$
g\left(\epsilon ; a_{l}, a_{r} ; B\right)=g^{b e t a}\left(\frac{\epsilon}{B} ; a_{l}, a_{r}\right)
$$

for a given fixed adjustment cost $\epsilon$. Hence, the support for the distribution above lies on the interval $0 \leq \epsilon \leq B$. The same procedure goes for the CDF as well. Next, using the specified distribution above, we can compute the expected level of cost of adjustment, $\Xi$, for a given proportion of firms adjusting, $\alpha$. Since in the model, $\alpha$ is the determined by the cutoff rule $v_{0}-v_{j}=w \bar{\epsilon}$, we can express $\Xi$ as a function of the fixed cost cutoff $\bar{\epsilon}$. This expression can be cast as

$$
\Xi(\bar{\epsilon})=B \int_{0}^{\bar{\epsilon} / B} x g^{\text {beta }}\left(x ; a_{l}, a_{r}\right) d x .
$$

For the parameters of the distribution, I choose $a_{l}=2.1$ and $a_{r}=1$. This leads to the following shapes for the CDF and PDF

\section{Appendix D: The start-up problem under linear-quadratic (LQ) framework}

This appendix serves to put forth the start-up problem, present in all optimal monetary policy models under precommitment with imperfect competition. I do this by considering optimal policy problem in a familiar linear-quadratic (LQ) framework, for example as in Clarida, et. al. (1999) with Calvo staggered pricing. I note some notational overlaps with the main text in the paper.

Here, the familiar model has two distortions present in the economy: the relative price distortion and the markup distortion due to monopolistically competitive firms that set prices according to 
Calvo's price setting. As in Woodford (2003) and Benigno and Woodford (2004, 2005), we can derive a quadratic loss function using the second order approximation to the utility function. I focus on the deterministic case and the case in which the size of the markup distortion is small in deriving the loss function. The more realistic stochastic case is not relevant for our purpose here since we can just consider the start-up problem assuming that the stochastic disturbances are zero. It is true that the size of the markup distortion will matter for how large the start-up effect is, but since our purpose is just to collect idea on the monetary authority's incentive to inflate, we can just assume a small markup distortion without any loss of generality - as long as there is a markup distortion, there would an incentive to inflate in the first period.

Given the discussion above, the monetary authority's objective function is thus given by

$$
L=-\frac{1}{2} E_{0}\left\{\sum_{t=0}^{\infty} \beta^{t}\left[\lambda\left(x_{t}-x^{*}\right)^{2}+\pi_{t}^{2}\right]\right\},
$$

where $x_{t}$ is the output gap, $\pi_{t}$ is the inflation rate (percentage change of price level from time $t-1$ to time $t$ ), and $x^{*}$ is the target output gap. The form of the loss function indicates that the monetary authority should seek to stabilize inflation around zero and the output gap around the target level $x^{*}$. To derive the loss function above, I assume that the momentary utility function is given by $u\left(c_{t}, n_{t}\right)=\log \left(c_{t}\right)-\varepsilon \frac{n_{t}^{1+v}}{1+v}$, with $c_{t}$ represents the Dixit-Stiglitz aggregate consumption. The production function for the monopolistically competitive firms is linear in labor and these firms hire labor competitively in a global labor market. Given these assumptions, it follows that $x^{*}=v \Phi=v\left(1-\frac{\theta-1}{\theta}\right)$, where $\theta$ is the elasticity the substitution across goods varieties. In this expression, $\Phi$ measures the inefficiency of steady state output level due to the markup distortion. Also, the relative weight on output gap stabilization is given by $\lambda=\frac{\kappa}{\theta}$, where $\kappa$ is the coefficient on the output gap in the Phillips curve

$$
\pi_{t}=\kappa x_{t}+\beta E_{t} \pi_{t+1}
$$

With Calvo's probability of non-adjustment denoted by $\alpha$ and assuming a unit output elasticity of real marginal cost, it follows that $\kappa=(1-\alpha)(1-\alpha \beta) / \alpha$.

The optimal policy under commitment then involves a benevolent monetary authority that selects a state-contingent sequence of output gap $x_{t}$ and inflation $\pi_{t}$ for all periods $t \geq 0$ by maximizing (32) subject to (33). ${ }^{44}$ The Lagrangian for the maximization problem is

$$
L_{0}=-\frac{1}{2} E_{0}\left\{\sum_{t=0}^{\infty} \beta^{t}\left\{\left[\alpha\left(x_{t}-x^{*}\right)^{2}+\pi_{t}^{2}\right]+\phi_{t}\left[\pi_{t}-\lambda x_{t}+\beta E_{t} \pi_{t+1}\right]\right\}\right\}
$$

where $\phi_{t}$ is the multiplier of the constraint. The optimality conditions therefore are

$$
\begin{gathered}
\alpha\left(x_{t}-x^{*}\right)-\frac{\lambda}{2} \phi_{t}=0 \\
\pi_{t}+\frac{1}{2} \phi_{t}-\frac{1}{2} \phi_{t-1}=0 \\
\pi_{0}+\frac{1}{2} \phi_{0}=0,
\end{gathered}
$$

\footnotetext{
${ }^{44}$ There is another constraint involving an aggregate demand condition (the IS curve equation), but this condition is not needed to solve for the optimal sequences of inflation and the output gap.
} 
where the first condition holds for all $t \geq 0$ and the second condition holds for all $t>0$. Equations (35) and (36) show that the monetary authority should treat the starting period $(t=0)$ differently than the subsequent periods. That is, the lagged multiplier associated with past commitments prior to the start-up period is zero, highlighting that there is no past commitment in the start-up period.

Following Marcet and Marimon (1999), we can cast the maximization problem into a recursive form. Formally, let's consider the following augmented Lagrangian:

$$
\begin{gathered}
V\left(\phi_{-1}, s_{0}\right)=\min _{\left\{\phi_{t}\right\}_{t=0}^{\infty}} \max _{\left\{\pi_{t}, x_{t}\right\}_{t=0}^{\infty}} \\
-\frac{1}{2} E_{0} \sum_{t=0}^{\infty} \beta^{t}\left\{\left[\lambda\left(x_{t}-x^{*}\right)^{2}+\pi_{t}^{2}\right]\right. \\
\left.-\phi_{t}\left(\kappa x_{t}\right)+\left(\phi_{t}-\phi_{t-1}\right)\right\}
\end{gathered}
$$

Recursively, the above Lagrangian can be written as

$$
\begin{gathered}
V\left(\phi_{t-1}, s_{t}\right)=\min _{\left\{\phi_{t}\right\}} \max _{\left\{\pi_{t}, x_{t}\right\}} \\
-\frac{1}{2}\left\{\left[\lambda\left(x_{t}-x^{*}\right)^{2}+\pi_{t}^{2}\right]+\beta E_{t} V\left(\phi_{t}, s_{t+1}\right)\right. \\
\left.-\phi_{t}\left(\kappa x_{t}\right)+\left(\phi_{t}-\phi_{t-1}\right)\right\} .
\end{gathered}
$$

Hence, by adding a lagged multiplier to the the policy problem, we get the same optimality conditions, given by (34) and (35), for all periods $t \geq 0$. One can interpret this lagged multiplier as the commitment that must be followed by the monetary authority. Note that equations (33), (34), and (35) are a system of difference equations, of which the stable stationary solutions are given by

$$
\begin{gathered}
x_{t}=\delta x_{t-1} \\
\phi_{t}=\delta \phi_{t-1}+\frac{2(\delta-1) \lambda}{\kappa} x^{*} \\
\pi_{t}=\delta \pi_{t-1},
\end{gathered}
$$

where $a \equiv \frac{\lambda}{\lambda(1+\beta)+\kappa^{2}}$ and $\delta=\frac{1-\sqrt{1-4 \beta a^{2}}}{2 a \beta} \in(0,1)$. The unique solution for optimal $\pi_{t}$ that is consistent with the initial condition $\phi_{-1}=0$ is given by ${ }^{45}$

$$
\pi_{t}=(1-\delta) \frac{\lambda}{\kappa} \delta^{t} x^{*}
$$

Equation (37) shows that inflation in the start-up period $t=0$ is higher than those in subsequent periods, illustrating that surprise inflation is optimal in the start-up period. Several comments on (37) are in order. First, the size of the start-up problem depends on several features of the model economy, with the size of the target output gap $x^{*}$ playing a prominent role. In this model setup, we can interpret the size of the target output gap $x^{*}$ as the size of the steady-state markup distortion in the economy - that is, the inefficiency in the economy due to firms' monopoly power. If there is no monopoly power, there would be no incentive to inflate since $x^{*}=0$ in this case. Equation (37) tells us that the monetary authority has an incentive to inflate only if the steady-state output is

\footnotetext{
${ }^{45}$ Using the same technique, we can also find the evolution of the output gap that is consistent with $\phi_{-1}=0$. This is given by $x_{t}=\delta^{t+1} x^{*}$.
} 
inefficient $\left(x^{*}>0\right)$. Put another way, the start-up problem is present because there is a markup distortion that still exists even under zero inflation, and the monetary authority can erode this markup distortion because there is no past commitment that must be respected in the start-up period $0\left(\phi_{-1}=0\right)$. The higher is the degree of inefficiency due to markup distortion (higher $\Phi$ and $x^{*}$ ), the higher would the start-up inflation be. The start-up effect will eventually die down with the rate $\delta$ per period.

What is the effect of the probability of non-adjustment $\alpha$ on the start-up problem? We can investigate this by decomposing (37) into period $t=0$ and the subsequent periods:

$$
\begin{gathered}
\pi_{0}=(1-\delta) \frac{1}{\theta} x^{*}, \\
\pi_{t}=\delta \pi_{t-1}, \forall t>0 .
\end{gathered}
$$

Note that I have used the fact that $\lambda=\kappa / \theta$ in deriving (38) from (37). One can show that the probability of price fixity $\alpha$ positively affects $\delta$ for given values of $\beta, v$, and $\theta$. Hence, based on (38), a higher $\alpha$ (more price stickiness) translates into lower start-up inflation in period 0 , for a given size of the steady-state markup distortion. This feature is related to the cost of higher inflation on the relative-price distortion: since a higher degree of price stickiness leads to a higher relative-price distortion for a given inflation rate, the optimal level of surprise inflation in the first period should be lower when $\alpha$ is higher. That is, the start-up inflation is lower if prices are stickier since the welfare cost of inflation is higher. Equation (39) shows that the speed of the transition of inflation back to its steady state level depends entirely on $\delta$. The higher is the probability of price fixity, the higher is $\delta$-hence, the slower the transition is. The figure below shows the evolution of inflation as in (37) for several parametrizations of $\alpha$, with all other parameters fixed at particular values. ${ }^{46}$

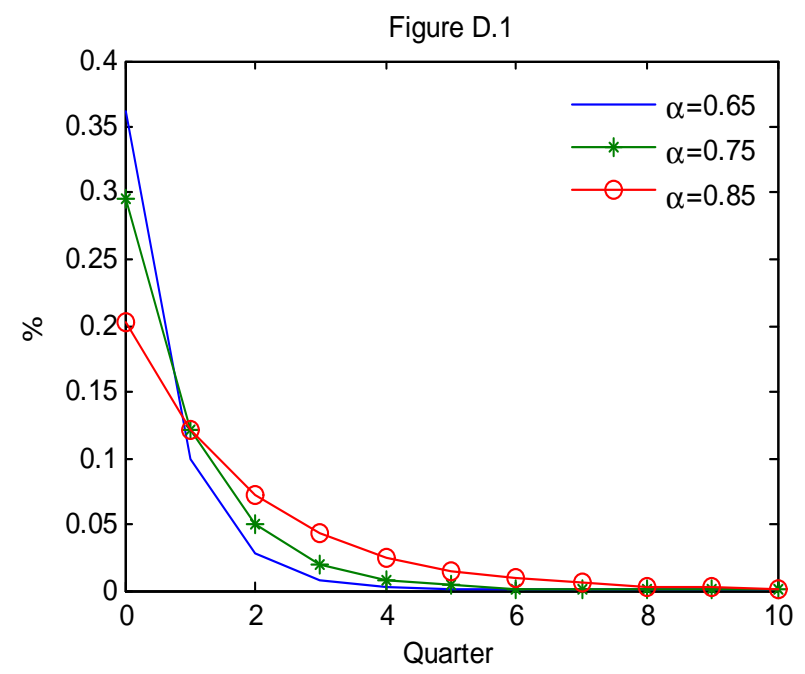

Note that we can draw a parallel between the above figure and the result on the start-up problem under SDP in the main text. Within this context, the economy under SDP can be approximately thought of as a Calvo model with a lower $\alpha$ (less price stickiness), provided that the relative stabilization weight $(\lambda)$ is appropriately adjusted.

\footnotetext{
${ }^{46}$ Specifically, I assume the following parameter values: $\beta=0.99, \theta=10$, and $v=0.5$.
} 